\title{
A Role for Auditory Corticothalamic Feedback in the Perception of Complex Sounds
}

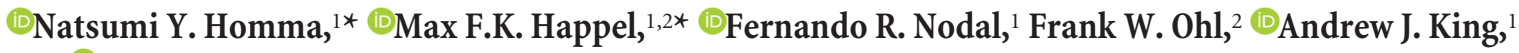 \\ and ${ }^{\circ}$ Victoria M. Bajo ${ }^{1}$ \\ ${ }^{1}$ Department of Physiology, Anatomy, and Genetics, University of Oxford, Oxford OX1 3PT, United Kingdom, and ${ }^{2}$ Department of Systems Physiology of \\ Learning, Leibniz Institute for Neurobiology, D-39118 Magdeburg, Germany
}

Feedback signals from the primary auditory cortex $(\mathrm{A} 1)$ can shape the receptive field properties of neurons in the ventral division of the medial geniculate body (MGBv). However, the behavioral significance of corticothalamic modulation is unknown. The aim of this study was to elucidate the role of this descending pathway in the perception of complex sounds. We tested the ability of adult female ferrets to detect the presence of a mistuned harmonic in a complex tone using a positive conditioned go/no-go behavioral paradigm before and after the input from layer VI in A1 to MGBv was bilaterally and selectively eliminated using chromophore-targeted laser photolysis. MGBv neurons were identified by their short latencies and sharp tuning curves. They responded robustly to harmonic complex tones and exhibited an increase in firing rate and temporal pattern changes when one frequency component in the complex tone was mistuned. Injections of fluorescent microbeads conjugated with a light-sensitive chromophore were made in MGBv, and, following retrograde transport to the cortical cell bodies, apoptosis was induced by infrared laser illumination of A1. This resulted in a selective loss of $\sim 60 \%$ of layer VI A1-MGBv neurons. After the lesion, mistuning detection was impaired, as indicated by decreased $d^{\prime}$ values, a shift of the psychometric curves toward higher mistuning values, and increased thresholds, whereas discrimination performance was unaffected when level cues were also available. Our results suggest that A1-MGBv corticothalamic feedback contributes to the detection of harmonicity, one of the most important grouping cues in the perception of complex sounds.

Key words: auditory cortex; behavior; chromophore-targeted laser photolysis; ferret; harmonic complex tones; medial geniculate body

Significance Statement

Perception of a complex auditory scene is based on the ability of the brain to group those sound components that belong to the same source and to segregate them from those belonging to different sources. Because two people talking simultaneously may differ in their voice pitch, perceiving the harmonic structure of sounds is very important for auditory scene analysis. Here we demonstrate mistuning sensitivity in the thalamus and that feedback from the primary auditory cortex is required for the normal ability of ferrets to detect a mistuned harmonic within a complex sound. These results provide novel insight into the function of descending sensory pathways in the brain and suggest that this corticothalamic circuit plays an important role in scene analysis.

\section{Introduction}

Investigating how the brain processes complex sounds is essential to understand auditory perception. Along the auditory pathway,

\footnotetext{
Received Feb. 9, 2017; revised April 12, 2017; accepted April 18, 2017

Author contributions: N.Y.H., M.F.K.H., F.R.N., F.W.O., A.J.K., and V.M.B. designed research; N.Y.H., M.F.K.H., F.R.N., and V.M.B. performed research; N.Y.H. and M.F.K.H. analyzed data; N.Y.H., M.F.K.H., F.R.N., F.W.O., A.J.K., and V.M.B. wrote the paper.

This research was supported by Wellcome Principal Research Fellowships (WT07650AIA and WT108369/Z/ 2015/Z) to A.J.K., a Japan Student Services Organization Scholarship to N.Y.H., an Action on Hearing Loss grant to V.M.B. and A.J.K., and a Postdoctoral Fellowship of the German Academic Exchange Service to M.F.K.H. We thank Jennifer Bizley, Kerry Walker, and Jan Schnupp for providing initial MATLAB code for the go/no-go behavior.

${ }^{*}$ N.Y.H. and M.F.K.H. contributed equally to this work.

The authors declare no competing financial interests.

Correspondence should be addressed to Victoria M. Bajo, Department of Physiology, Anatomy and Genetics,

Sherrington Building, Parks Road, 0xford OX1 3PT, UK. E-mail: victoria.bajo@dpag.ox.ac.uk.
}

there is a clear change in response properties from the inferior colliculus (IC), via the auditory thalamus to the auditory cortex, suggesting that the medial geniculate body (MGB) in the thalamus may be a key stage in transforming or gating the representation of sounds in the brain (Miller et al., 2002; Las et al., 2005; Bartlett and Wang, 2007). Furthermore, its complex serial and parallel connectivity patterns suggest that MGB has a far more complex role in hearing than simply being an obligatory relay

N.Y. Homma's present address: Coleman Memorial Laboratory, Center for Integrative Neuroscience, Department of Otolaryngology-Head \& Neck Surgery, University of California, San Francisco, San Francisco, CA 94115.

DOI:10.1523/JNEUROSCI.0397-17.2017

Copyright $\odot 2017$ Homma, Happel et al.

This is an open-access article distributed under the terms of the Creative Commons Attribution License Creative Commons Attribution 4.0 International, which permits unrestricted use, distribution and reproduction in any medium provided that the original work is properly attributed. 
station between midbrain and cortex (Sherman and Guillery, 2011; Lee, 2013).

The descending corticothalamic projection from layer VI in primary auditory cortex (A1) to the ventral division of MGB (MGBv) is one of the largest feedback pathways in the auditory system (Rouiller and Welker, 1991; Ojima, 1994; Bajo et al., 1995; Prieto and Winer, 1999), with a key potential role in modulating the receptive field properties and temporal firing patterns of thalamic neurons (He, 1997). Indeed, changes in response properties, such as sharpened tuning curves and shifts in best frequency, have been observed following local inactivation of Al (Zhang et al., 1997). Cortical stimulation or inactivation experiments have also demonstrated comparable corticothalamic modulation in the visual (Andolina et al., 2007; Wang et al. 2016) and somatosensory (Ghazanfar et al., 2001; Temereanca and Simons, 2004) systems.

Acute pharmacological inactivation of auditory cortex has been demonstrated to yield immediate deficits in the discrimination of basic sound properties (Talwar et al., 2001; Jaramillo and Zador, 2011). However, the extent to which compensatory plasticity occurs following cortical inactivation seems to depend on the spectrotemporal complexity of the stimulus. For example, cortical ablation has little effect on frequency discrimination behavior using pure tones but impairs frequency-modulated tone discrimination (Ohl et al., 1999; Ono et al., 2006; Rybalko et al., 2006; Wetzel et al., 2008). Moreover, previous studies indicate that bottom-up and top-down processing streams are integrated in auditory cortex by recurrent cortico-thalamo-cortical interactions (Barth and MacDonald, 1996; Happel et al., 2014). Hence, disentangling these streams using appropriate manipulation strategies should provide mechanistic insight beyond the information inferred from silencing entire brain regions. In this study, we sought to determine what role corticothalamic feedback might play in auditory perception by examining the effects of selective elimination of corticothalamic projection neurons on the ability of ferrets to detect frequency shifts ("mistuning") in harmonic complex tones (HCTs).

If two complex tones, such as a pair of vowels, are presented simultaneously, they are more likely to be heard as distinct sounds if their fundamental frequencies differ (de Cheveigné et al., 1997). Harmonicity is therefore an important cue in grouping together the different frequency components of each sound, so that they can be segregated from other concurrent sounds. This can be demonstrated by mistuning one of the frequency components in an HCT, which, in humans, may then be heard as a separate tone with a pitch that differs from that corresponding to the fundamental frequency of the HCT (Moore et al., 1985; Hartmann et al., 1990). The ability to discriminate mistuned complex tones (MCTs) from HCTs has also been measured behaviorally in various nonhuman species (Lohr and Dooling, 1998; Klinge and Klump, 2009, 2010; Homma et al., 2016), and sensitivity to mistuning has been investigated electrophysiologically, both in A1 and at subcortical levels of the auditory pathway (Sinex et al., 2002, 2003, 2005; Sinex, 2008; Fishman and Steinschneider, 2010).

In the present study, the mistuning detection paradigm was combined with chromophore-targeted laser photolysis in pigmented ferrets (Mustela putorius furo). This method has been shown to induce apoptosis in retrogradely labeled neurons (Macklis, 1993; Magavi et al., 2000) and can be combined with behavioral measurements (Bajo et al., 2010). By selectively eliminating the unidirectional projection from $\mathrm{Al}$ to the $\mathrm{MGBv}$, we show that corticothalamic feedback contributes to an important aspect of auditory perception.
Table 1. Summary of animals and techniques used in this study

\begin{tabular}{|c|c|c|c|}
\hline Ferret no. & Recordings in the MGB & $\begin{array}{l}\text { Mistuning } \\
\text { behavior }\end{array}$ & $\begin{array}{l}\text { Chromophore-targeted } \\
\text { laser photolysis }\end{array}$ \\
\hline F1418 & $\boldsymbol{V}$ (Complex tones) & & \\
\hline F1442 & $\boldsymbol{V}$ (Complex tones) & & \\
\hline F1443 & $\mathcal{V}$ (Complex tones) & & \\
\hline F1205 & レ & レ & $\boldsymbol{V}$ (A1-MGBv lesion) \\
\hline F1209 & $\swarrow$ & $\swarrow$ & レ(A1-MGBv lesion) \\
\hline F1430 & & レ & $\boldsymbol{V}($ A1-MGBv lesion) \\
\hline F1223 & レ & レ & Control \\
\hline $\mathrm{F} 1225$ & $\swarrow$ & レ & Control \\
\hline$F 1325$ & $レ$ & レ & Control \\
\hline F1433 & & レ & Control \\
\hline F1444 & & レ & Control \\
\hline F0416 & & & Control (Anatomy) \\
\hline
\end{tabular}

The check symbol $(\boldsymbol{\sim})$ indicates that the procedures were performed on the animal.

\section{Materials and Methods}

Twelve adult female ferrets sourced from Marshall BioResources were used in this study (Table 1). All experimental procedures were approved by the local ethical review committee and were performed under license from the UK Home Office in accordance with the Animal (Scientific Procedures) Act (1986, amended in 2012).

To identify the MGBv, recordings were performed using linear multichannel electrode arrays (NeuroNexus). This information was used to target injections of fluorescent microspheres conjugated with a lightsensitive chromophore into the MGBv to kill descending projection neurons located in layer VI in A1 by laser photolysis (Sheen and Macklis, 1995; Bajo et al., 2010). Animals were tested using a go/no-go behavioral paradigm (Homma et al., 2016) before and after this feedback pathway was removed (Table 1 ).

\section{MGBv identification}

Surgical procedure. Anesthesia was induced with a single intramuscular injection of medetomidine hydrochloride $(0.022 \mathrm{mg} / \mathrm{kg}$ body weight; Domitor, Orion Pharma) and ketamine hydrochloride $(5 \mathrm{mg} / \mathrm{kg}$; Narketan10, Vetoquinol), and maintained with an intravenous infusion $(3-4 \mathrm{ml} / \mathrm{h})$ of medetomidine hydrochloride $(0.022 \mathrm{mg} / \mathrm{kg} / \mathrm{h})$ and ketamine hydrochloride $(5 \mathrm{mg} / \mathrm{kg} / \mathrm{h})$ in $0.9 \%$ saline solution supplemented with $5 \%$ glucose. Atropine sulfate $(0.06 \mathrm{mg} / \mathrm{kg}$, s.c.; Atrocare, Animalcare $)$ and dexamethasone $(0.5 \mathrm{mg} / \mathrm{kg}$, s.c.; Dexadreson, Intervet UK) were administered to minimize pulmonary secretions and prevent cerebral edema, respectively. Doxapram hydrochloride (4 mg/kg, s.c.; Dopram-V Injection, Pfizer) was administered to maintain respiratory rate. Perioperative analgesia was provided with buprenorphine hydrochloride $(0.01 \mathrm{mg} / \mathrm{kg}$, s.c.; Vetergesic, Sogeval UK) and meloxicam $(0.2 \mathrm{mg} / \mathrm{kg}$, s.c.; Metacam, Boehringer Ingelheim). Depth of anesthesia, respiratory rate, EKG, and end-tidal $\mathrm{CO}_{2}$ were monitored and maintained throughout the experiment. Temperature was monitored using a rectal probe and was maintained at $38^{\circ} \mathrm{C}$ using a forced-air warming system (Bair Hugger, 3M Health Care).

The ferret was placed in a stereotaxic frame, the eyes were protected with a carbomer liquid eye gel (Viscotears, Alcon Laboratories), the skull was exposed, and a stainless steel bar was attached above the mid-sagittal ridge using dental cement. After craniotomies were made, animals were moved to an anechoic chamber. Once the dura mater was removed, a single- or double-shank silicon probe (NeuroNexus), with 16 or $16 \times 2$ recording sites vertically arranged and spaced at $100 \mu \mathrm{m}$ intervals, was inserted $1.8-2.5 \mathrm{~mm}$ anterior to the caudal end of the ectosylvian gyrus and 3.9-4.7 $\mathrm{mm}$ lateral from the midline. The probe was slowly advanced perpendicularly to the pial surface while recording neural activity in response to visual and auditory stimuli. The probe was advanced until exclusively auditory responses were encountered $(\sim 9 \mathrm{~mm})$.

Stimulus presentation. Stimulus generation and data acquisition were controlled with a PC using BrainWare software (Tucker-Davis Technologies) and by running customized MATLAB scripts (MathWorks), which communicated with system 3 RP2 and RX5 real-time signal processors (Tucker-Davis Technologies). All auditory stimuli were delivered bilaterally using Panasonic headphone drivers (RPHV297), with an in- 
verse filter generated by closed field calibrations using a one-eighth inch condenser microphone (Type 4138, Brüel and Kjær). Visual stimuli were delivered from an amber light-emitting diode (LED; $2.7 \mathrm{~V}$; light amplitude, $20 \mathrm{~mA}$; diameter, $12.7 \mathrm{~mm}$ ), located $20 \mathrm{~cm}$ in front of the head of the animal.

In the terminal recording experiments ( $n=3$; Table 1$)$, auditory stimuli comprised broadband noise bursts (with a low-pass cutoff frequency of $30 \mathrm{kHz} ; 100 \mathrm{~ms}$ duration; SPL range, $50-90 \mathrm{~dB}$ in $10 \mathrm{~dB}$ steps), which were sometimes paired with a simultaneous visual stimulus (100 ms), as well as pure tones and complex tones. Pure tones $(100 \mathrm{~ms}$, with $5 \mathrm{~ms}$ cosine ramps) ranged in frequency from 0.1 to $32 \mathrm{kHz}$ in one-fourth octave steps and between 0 and $80 \mathrm{~dB}$ SPL in $10 \mathrm{~dB}$ increments. Each frequency-level combination was presented pseudorandomly five or more times at a rate of $1 \mathrm{~Hz}$. To avoid long surgical recovery sessions, a simplified version of the frequency/level combinations $(0.5-20 \mathrm{kHz}$, one-third octave steps, four intensities from 60 to $90 \mathrm{~dB} \mathrm{SPL}$ ) was used in the animals in which chromophore-targeted laser photolysis was performed (Table 1).

Complex tones (350 ms duration) were used in terminal recordings (Table 1). They comprised 16 harmonics with a $400 \mathrm{~Hz} F_{0}$, referred to hereafter as HCTs. MCTs were generated by shifting the second, fourth, or eighth harmonic to a higher frequency by $0.05 \%, 0.2 \%, 0.8 \%, 3 \%$, or $12 \%$. The complex tones were smoothed by a $25 \mathrm{~ms}$ Hanning window at the beginning and end to reduce side lobes in the frequency spectrum. The overall SPLs varied from 40 to $90 \mathrm{~dB}$ in $10 \mathrm{~dB}$ steps, and each complex tone was presented pseudorandomly 5-10 times at a rate of $1 \mathrm{~Hz}$.

Response properties and criteria for MGBv identification. In a typical penetration (Fig. 1), visual responses in the cortex were first observed up to a depth of $\sim 4 \mathrm{~mm}$ below the pial surface. This activity was followed by large-amplitude spikes with a high spontaneous activity from $\sim 4$ to $5.5 \mathrm{~mm}$ deep, which we identified as the hippocampus (Fig. $1 A, B$ ). Strong responses to light flashes from an LED were obtained from $\sim 5.5$ to $7.5 \mathrm{~mm}$ below the surface, corresponding to the visual thalamus, the lateral geniculate nucleus (LGN; Fig. 1C). Finally, auditory responses to broadband noise were recorded from $\sim 7.5$ to $9 \mathrm{~mm}$ deep in the auditory thalamus (Fig. 1D). Once acoustically responsive units were identified, a set of pure tones was presented to characterize the frequency tuning of the units. In addition, in three animals (Table 1), we used complex tones to investigate the responses of MGBv neurons to HCTs and MCTs.

Supervised spike sorting and clustering was performed off-line in BrainWare on the basis of different spike features (e.g., amplitude, width and area) and interspike intervals. The spike timing data were exported for further analysis in MATLAB. Only the data where spike counts in a $150 \mathrm{~ms}$ window following stimulus presentation for visual stimuli, broadband noise, and pure tones, or a $450 \mathrm{~ms}$ window for complex tones, were significantly different from the spike counts in the same duration window at the end of the sweep were analyzed (paired $t$ tests, $p<0.01$ ). Differences between responses to different stimulus types were confirmed by a one-way ANOVA and post hoc Tukey-Kramer tests $(p<$ 0.01 ) for the responses to light flashes and noise bursts. Pooled peristimulus time histograms (PSTHs) were obtained by summing spike counts per bin (1 ms) across stimulus repetitions. Peak response latencies were computed as the time in milliseconds until the highest spike rate was driven in the pooled response, and minimum response latencies were computed as the time until the spike rate first exceeded a criterion defined as $20 \%$ of the difference between peak and mean spontaneous firing rates (Bizley et al., 2005).

Frequency response areas (FRAs) were determined from the summed activity for each combination of tone level and frequency (Fig. 1E). The threshold at each frequency was used to construct tuning curves using the mean spontaneous rate $+0.2 \times$ (maximum firing rate - mean spontaneous rate) as a response criterion (Sutter and Schreiner, 1991; Bizley et al., 2005; Moshitch et al., 2006), and minimum thresholds and characteristic frequencies (CFs) were determined. Frequency selectivity was estimated by calculating the Q10 (CF divided by the bandwidth at $10 \mathrm{~dB}$ above threshold) and BW30 (the bandwidth at $30 \mathrm{~dB}$ above threshold).

The MGBv limits were established based on the responses to pure tones for units showing sharp tuning curves, clear CFs, and short laten- cies. In addition, the responses to complex tones in MGBv units were always robust. For units that exhibited a sustained response throughout the duration of the complex tone (73\% of the units), the synchronization index (SI; Young and Sachs, 1979) was calculated by performing a fast Fourier transform of the PSTHs for the sustained portion of their response (51-350 ms; Fig. 2).

\section{Chromophore-targeted laser photolysis}

Chlorin $\mathrm{e}_{6}$ monoethylene diamine monoamide disodium salt (Frontier Scientific) was activated with $N$-cyclohexyl- $N^{\prime}$-(2-morpholinoethyl) carbodiimide methyl- -toluenesulfonate (C106402, Sigma-Aldrich) and attached to the surface of fluorescent microbeads (red and green Retrobeads IX, Lumafluor). The reaction was stopped after $1 \mathrm{~h}$ with $0.1 \mathrm{M}$ glycine buffer, $\mathrm{pH} 8$, and a pellet was produced by several periods of high-speed centrifugation $(169,537 \mathrm{~g})$ and suspended in PBS.

Injections of active conjugated microbeads were made in the MGBv (red in the left hemisphere and green in the right) in the lesion animals at the stereotaxic coordinates previously determined by recordings. A glass micropipette with a 15-30 $\mu \mathrm{m}$ tip diameter attached to a microinjector (Nanoject II, Drummond Scientific) was placed in a total of five different positions in MGBv, and $50.6 \mathrm{nl}$ was injected by pressure at each position. In control animals, we injected inactive microbeads or just PBS at the same coordinates. In addition, in two other control cases, we injected active conjugated microbeads but in a different location within the brain (for details, see Table 2). One additional control animal (F0416) was used to anatomically assess the relative strength of the projection to the MGBv from different regions of auditory cortex. Ten percent biotinylated dextran amine (BDA; dextran biotin fixable; molecular weight 10,000; Invitrogen) was iontophoretically injected ( $+5 \mu \mathrm{A}$; half duty cycle, $7 \mathrm{~s} ; 15 \mu \mathrm{m}$ tip diameter; $10 \mathrm{~min}$ ) at the MGBv coordinates determined from the recording experiments.

The same surgical procedure was followed as described earlier, but, in addition to the perioperative analgesia provided, amoxicillin and clavulanic acid (20 mg/kg, s.c.; Synulox, Pfizer) were administered over 5 postsurgery days.

A second surgery under isoflurane $\left(1-3 \%\right.$ in $1 \mathrm{~L}$ of $\mathrm{O}_{2}$; IsoFlo, Abbot Laboratories) was performed 3-4 weeks later in lesion and control animals, with the exception of the anatomical control. Craniotomies were made bilaterally over A1 in the middle ectosylvian gyrus (MEG). A1 was exposed to near-infrared light from a laser diode $(\lambda=670 \mathrm{~nm}, 280 \mathrm{~mW}$, 10 min; Flatbeam-Laser 670, Schäfter + Kirchhoff) to induce apoptosis in retrogradely labeled cells. The laser light was adjusted with beamshaping optics (OPTC 5M-G25-60sMA) to create a $1.35 \mathrm{~mm}$ spot focused at the level of layer VI, $\sim 1 \mathrm{~mm}$ from the pial surface.

\section{Mistuning detection behavior}

Behavioral paradigm. The animals were trained by positive reinforcement with water reward using a go/no-go paradigm (Homma et al., 2016; Fig. 3). Blocks of 5 or $14 \mathrm{~d}$ of training were interspersed with 2 or $3 \mathrm{~d}$ off, respectively.

The reference and target stimuli were HCTs and MCTs, respectively, and started in sine phase with a $400 \mathrm{~Hz} F_{0}$ value and with the same duration and harmonic components previously described (Fig. 3B). The target stimulus had the fourth harmonic shifted to a higher frequency. We produced sets of target stimuli with varying degrees of mistuning that initially ranged from 0.5 to $192 \mathrm{~Hz}$ in 16 equal logarithmic steps, and later extended this range to include $0.1 \mathrm{~Hz}$ over a total of 23 steps.

The animals were first trained to maintain a nose poke at the trigger spout for variable periods of time $(0.2-2.0 \mathrm{~s})$ and then to break contact with this spout to obtain a reward at the other spout when two identical target MCTs with the fourth harmonic shifted by $200 \mathrm{~Hz}$ were presented (go signal) at $70 \mathrm{~dB}$ SPL. In the last part of the training, reference tones (no-go signal) were introduced at an initial level of $30 \mathrm{~dB}$ SPL. The level difference between the target and reference tones was gradually reduced as the performance of the animals improved by increasing the level of the reference until all stimuli were presented at $70 \mathrm{~dB}$ SPL. The number of reference tones preceding the two target tones on go trials was randomized from two to six to reduce the predictability of the timing of the target tones (Fig. 3C; for further details, see Homma et al., 2016). 


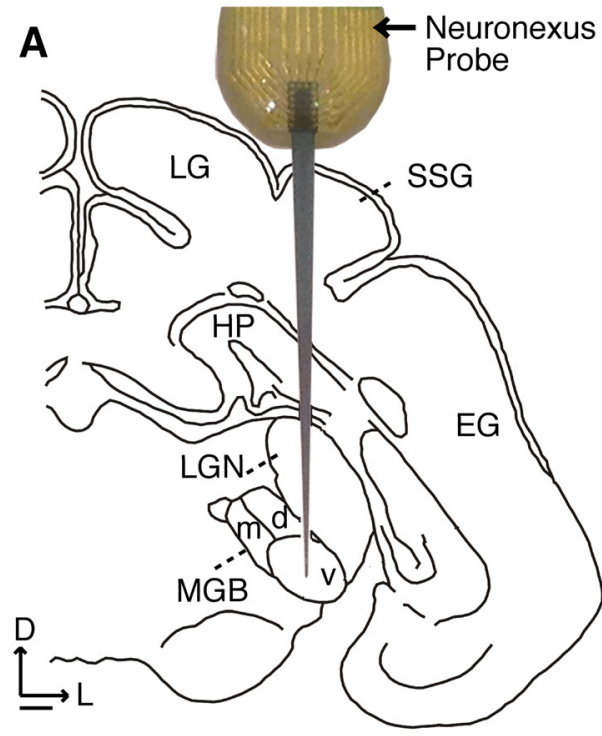

C

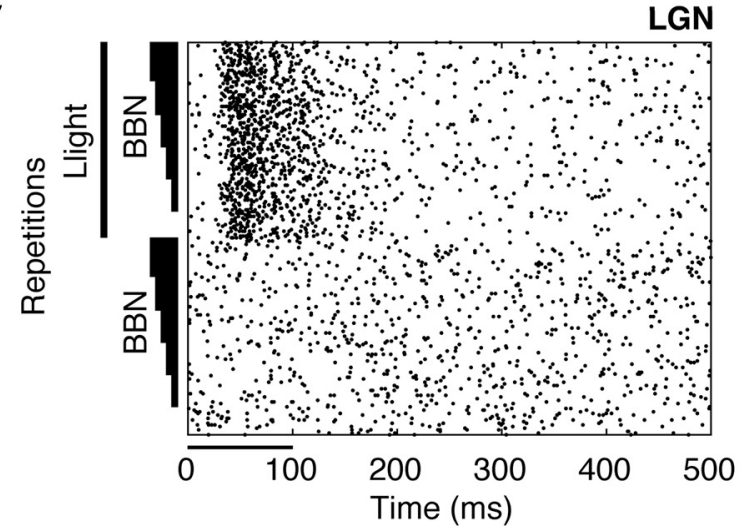

$\mathbf{E}$

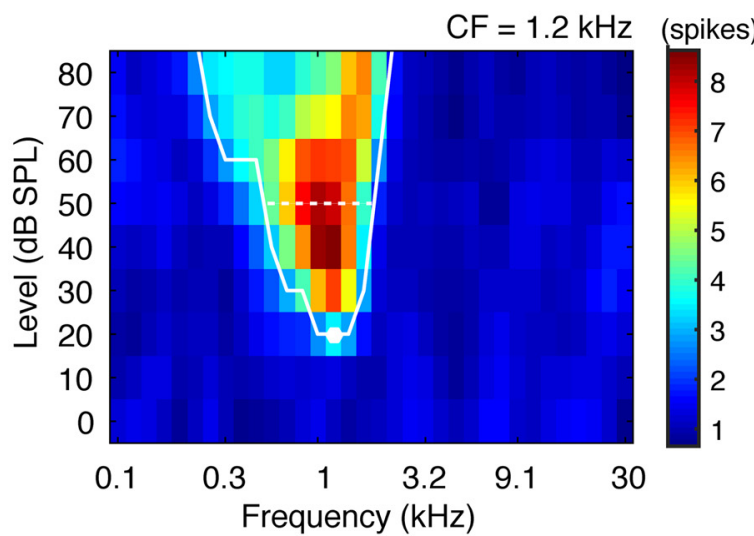

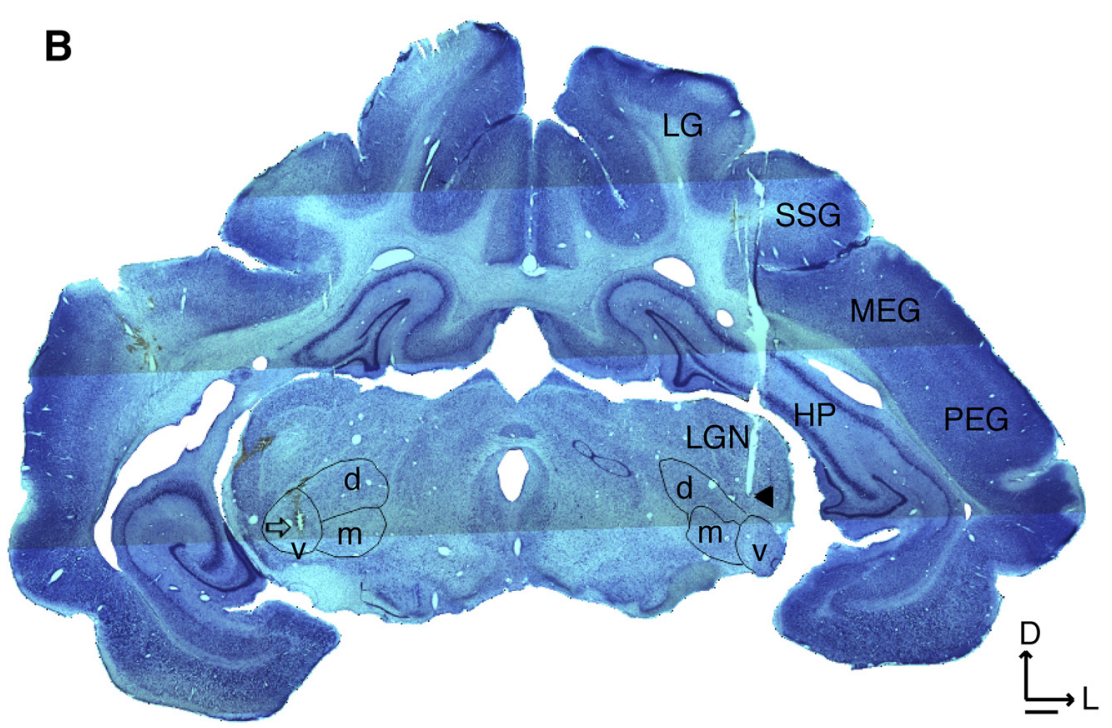

D

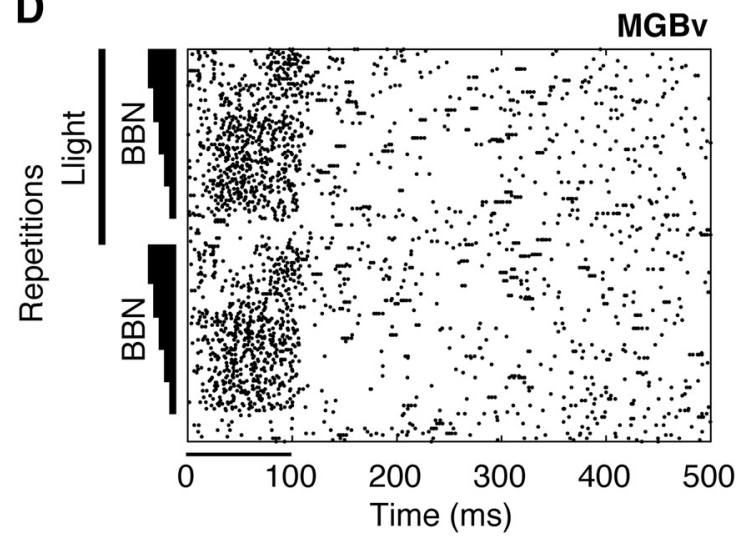

$\mathbf{F}$

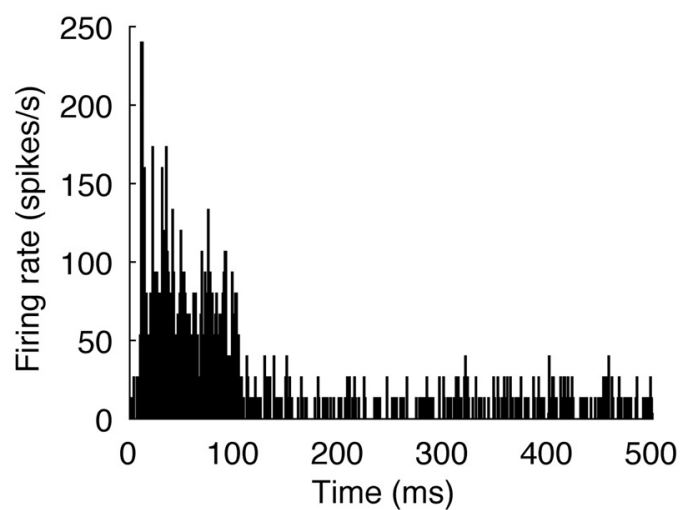

Figure 1. Identification of the ventral division of MGB. $A$, Schematic of the recording probe (NeuroNexus; 16 recording sites, $100 \mu \mathrm{m}$ apart) placed dorsoventrally through the cortex into $\mathrm{LGN}$ and MGB. $\boldsymbol{B}$, Coronal section of the midbrain indicating the location of the electrode tracks (arrow in the left MGBv and arrowhead in the right LGN). $C, D$, Examples of responses to stimulation with broadband noise (BBN) alone or combined with light flashes from an amber LED in the visual $(\boldsymbol{C})$ and auditory $(\boldsymbol{D})$ thalamus. The lines parallel to the $y$-axis indicate the light stimulus, and the triangular bars represent the BBN stimuli increasing in amplitude from 50 to $90 \mathrm{~dB}$ SPL in $10 \mathrm{~dB}$ steps (20 repetitions). The stimulus duration is indicated by the horizontal bar beneath each plot starting at time 0 . $E$, Example of a sharply tuned V-shaped FRA of multiunit activity recorded in MGBv. The white line indicates the tuning curve. CF is depicted by the white dot, and the white dashed line indicates the bandwidth at $30 \mathrm{~dB}$ above threshold. The color scale represents the number of spikes evoked at each frequency-level combination during the $100 \mathrm{~ms}$ stimulus. $F$, Example PSTH of responses to pure tones at unit CF in MGBv. D, Dorsal; d, dorsal MGB; EG, ectosylvian gyrus; $H P$, hippocampus; L, lateral; LG, lateral gyrus; m, medial MGB; MEG, middle ectosylvian gyrus; PEG, posterior ectosylvian gyrus; SSG, suprasylvian gyrus; $V$, ventral MGB. Scale bars: $A, B, 1 \mathrm{~mm}$.

Trials were self-initiated by the animals by licking the trigger spout. After misses (staying at the trigger spout after the target tones were presented) or early releases (leaving the trigger spout while the reference tones were being presented), a noise burst was played as feedback and to signal the lack of reward. Following a miss, a $1 \mathrm{~s}$ time-out was given, whereas a $12 \mathrm{~s}$ time-out was used after early releases to reinforce the performance of the animals on trials that required a long waiting time. The probability of trials that comprised reference tones only (no-go 
A

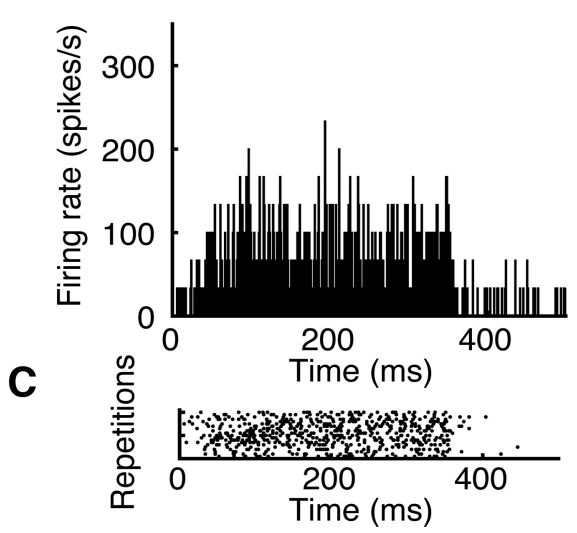

$\mathbf{E}$

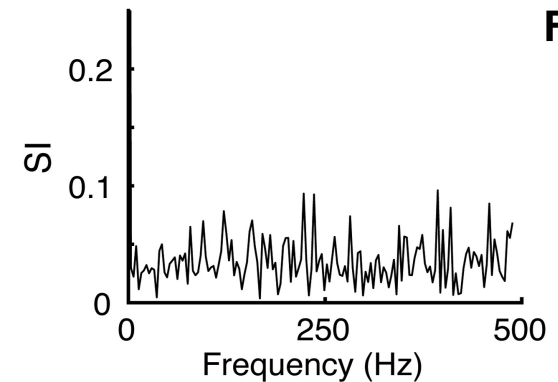

G

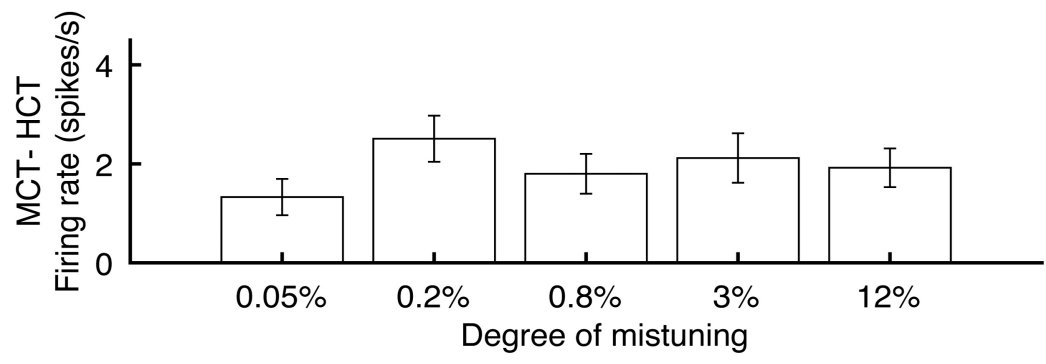

Figure 2. Responses to complex tones in MGBv. $A, B$, PSTHs showing the responses of one MGBv unit to 350 ms harmonic $(A)$ and mistuned $(\boldsymbol{B})$ complex tones. HCTs comprised 16 harmonics with a $400 \mathrm{~Hz} F_{0}$. In this example, for the MCT, the fourth harmonic was shifted by $192 \mathrm{~Hz}(12 \%)$. C, $\boldsymbol{D}$, Raster plots corresponding to $\boldsymbol{A}$ and $\boldsymbol{B}$, respectively. $\boldsymbol{E}, \boldsymbol{F}$, Temporal response patterns to HCTs $(\boldsymbol{C})$ and MCTs (D) demonstrated using the SI. G, MCTs elicited higher firing rates than HCTs in MGBv units. Bars indicate the difference of firing rate from that evoked by the HCT (mean \pm SEM) for each stimulus condition grouped by degree of mistuning $(0.05 \%, 0.2 \%, 0.8 \%, 3 \%$ or $12 \%)$. Firing rate increased when $M\left(T\right.$ s were presented (repeated-measures ANOVA, $F_{(5,290)}=7.4, p=8.2 \times 10^{-5}$ ), so long as the frequency of the mistuned harmonic fell within the FRA bandwidth of the unit at $30 \mathrm{~dB}$ above threshold.

Table 2. Location and type of injection for the lesion and control groups

\begin{tabular}{|c|c|c|c|c|}
\hline \multirow[b]{2}{*}{ Ferret no. } & \multirow{2}{*}{$\begin{array}{l}\text { Chromophore-targeted } \\
\text { laser photolysis }\end{array}$} & \multirow{2}{*}{$\begin{array}{l}\text { Injection of } \\
\text { microbeads }\end{array}$} & \multicolumn{2}{|l|}{ Injection sites } \\
\hline & & & Left & Right \\
\hline $\mathrm{F} 1205$ & $\boldsymbol{\nu}($ A1-MGBv lesion) & $\boldsymbol{\nu}$ (Active) & MGBV & MGBV \\
\hline F1209 & $\boldsymbol{\nu}($ A1-MGBv lesion) & $\boldsymbol{\nu}$ (Active) & MGBv & MGBd\&v \\
\hline $\mathrm{F} 1430$ & $\boldsymbol{\nu}(\mathrm{A} 1-M G B v$ lesion) & $\boldsymbol{\nu}$ (Active) & $M G B v$ & MGBv \\
\hline $\mathrm{F} 1223$ & Control & $\boldsymbol{W}$ (Inactive) & MGBm & LV \\
\hline $\mathrm{F} 1225$ & Control & $\boldsymbol{W}$ (Inactive) & LGN & LGN \\
\hline $\mathrm{F} 1325$ & Control & PBS & - & - \\
\hline F1433 & Control & $\boldsymbol{\nu}$ (Active) & Hippocampus & PPTg \\
\hline F1444 & Control & $\boldsymbol{\nu}$ (Active) & Rostral pole of IC & Hippocampus \\
\hline F0416 & Control (Anatomy) & BDA & MGBv & - \\
\hline
\end{tabular}

$\mathrm{LV}$, lateral ventricle; PPTg, pedunculopontine tegmental nucleus. Other abbreviations as in Fig. 1 legend. The check symbol $(\boldsymbol{\sim})$ indicates that the procedures were performed on the animal.

trials) was initially $10 \%$ and increased to $20 \%$ in the last four animals to reduce the number of early releases.

Data analysis. Behavioral performance was assessed by the overall correct response rate (number of correct responses on go trials and correct rejections on no-go trials divided by the total number of trials), hit rate (number of correct responses on go trials/total number of go trials) and false alarm (FA) rate (number of incorrect responses on no-go trials/total number of no-go trials). Individual sessions with FA rates $>0.60$, likely indicating a lack of attention, were excluded from the analysis.

Using signal detection theory (Wickens, 2002), a sensitivity index $\left(d^{\prime}\right)$ was calculated for each degree of mistuning from the $z$-transformed hit rate and FA rate according to the following formula:

$$
d^{\prime}=Z \text { (hit rate) }-Z \text { (FA rate) }
$$

We estimated psychometric functions by smoothing the $d^{\prime}$ values based on a model-free estimation (Zychaluk and Foster, 2009), with a weighting function assigned using a triangular kernel function (bandwidth, $40 \mathrm{~Hz}$ ). The thresholds were defined as the first point to cross the criterion $d^{\prime}=1$, which corresponds to a hit rate of 0.77 with a 0.40 FA rate. Mean psychometric functions were derived by fitting the smoothed $d^{\prime}$ values using unconstrained nonlinear optimization to a cumulative Gaussian distribution, as follows:

$$
\begin{aligned}
& D^{\prime}(x \mid \alpha, \beta, \mu, \sigma) \\
& \quad=\alpha\left(\frac{1}{\sigma \sqrt{2 \pi}} \int_{-\infty}^{x} e^{\frac{-(t-\mu)^{2}}{2 \sigma^{2}}} d t\right)+\beta,
\end{aligned}
$$

where $x$ is the degree of mistuning (in hertz) on a log scale, $\alpha$ and $\beta$ are constants to rescale the function in the $y$ direction, $\mu$ is the mean, and $\sigma$ the SD.

Response bias was estimated by calculating the following:

$$
\lambda_{\text {center }}=-\frac{1}{2} \times[\mathrm{Z}(\text { hit rate })+\mathrm{Z}(\text { FA rate })] \text {, }
$$

where $\lambda_{\text {center }}$ is a measure of displacement of the decision criterion. A value of zero indicates no bias in hit and FA rate, whereas positive values imply a lower hit rate and a higher FA rate, and negative values imply a higher hit rate and a lower FA rate.

The area under the curve (AUC) was obtained using the trapezoidal rule for numerical integration over the smoothed $d^{\prime}$ values on a log scale from the minimum to maximum degree of mistuning used.

\section{Histology and stereology}

After behavioral testing was complete or at the conclusion of terminal recordings (Table 1$)$, the animals were sedated $(0.022 \mathrm{mg} / \mathrm{kg}$, i.m.; Domitor), if awake, overdosed with pentobarbital sodium $(2 \mathrm{ml}$ of $200 \mathrm{mg} / \mathrm{ml}$, i.p.; Euthatal, Merial Animal Health) and perfused transcardially with $300 \mathrm{ml}$ of $0.9 \%$ saline solution (w/v) and $1 \mathrm{~L} 4 \%$ paraformaldehyde $(\mathrm{w} / \mathrm{v})$ in $0.1 \mathrm{M}$ phosphate buffer (PB), $\mathrm{pH}$ 7.4.

The brain was dissected from the skull, post-fixed with the same fixative, and cryoprotected with $30 \%$ sucrose in $0.1 \mathrm{M} \mathrm{PB}$. Coronal sections, $45 \mu \mathrm{m}$ thick, were obtained using a freezing microtome (SM2000 R sliding microtome, Leica Biosystems). In animals that only underwent electrophysiological recordings (Table 1), sections were Nissl stained $(0.5 \%$ cresyl violet $)$ and the positions of the electrode penetrations were confirmed under the microscope. Photographs of the sections were taken using a DMR microscope (Leica Microsystems) equipped with a digital camera (Microfire, Optronics). The anatomical control (F0416) only had 
A

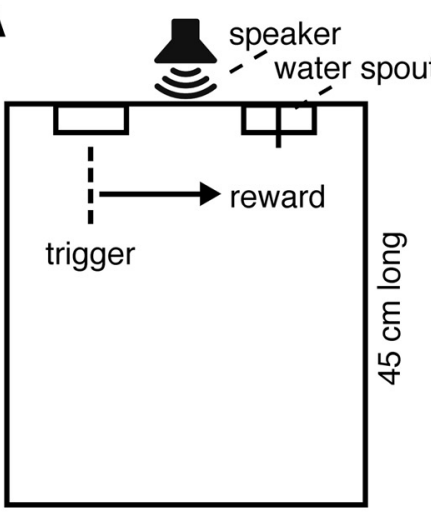

$40 \mathrm{~cm}$ wide
B

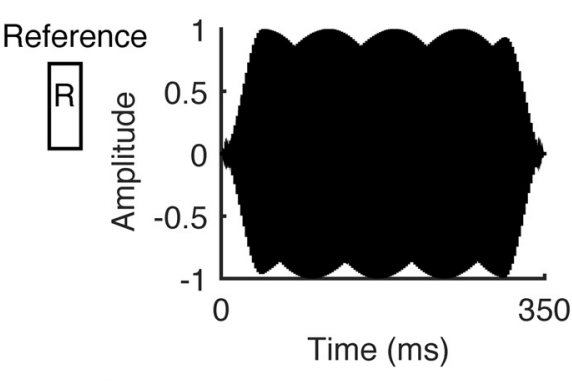

No-go trial

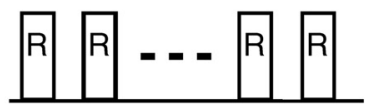

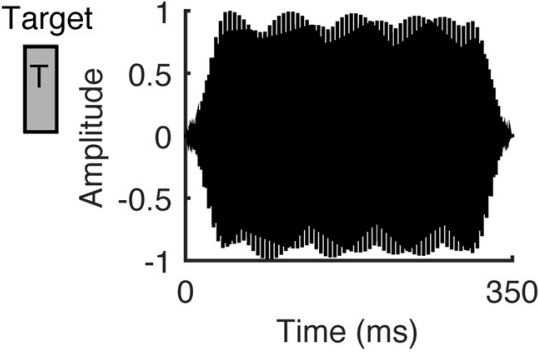

Go trial

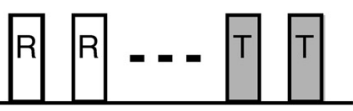

D

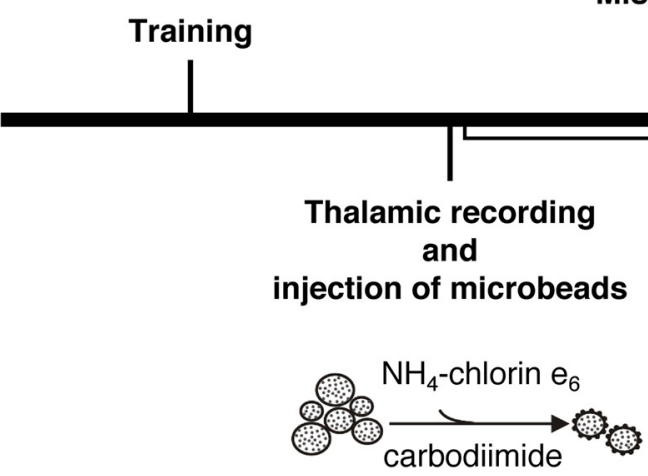

Mistuning detection test pre-laser
Mistuning detection test post-laser
E

Left

Rhodamine beads

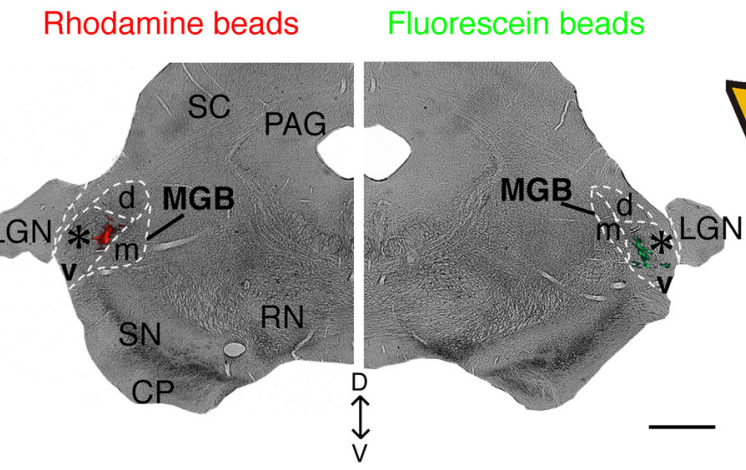

F

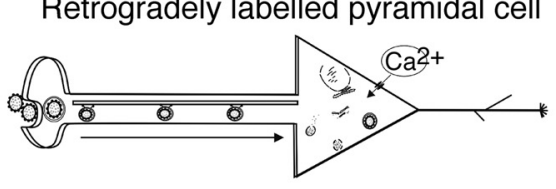

Chromophore-targeted laser photolysis

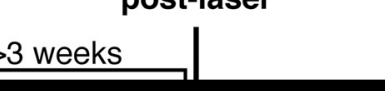

$>6$ weeks 
The location and extent of the microbead injection sites in the thalamus were determined, and the number of retrogradely labeled cells in the auditory cortex was quantified using a fluorescence microscope fitted with filters for fluorescence (448 or $530 \mathrm{~nm}$ light emission for green and red, respectively).

NeuN immunostaining was performed on free-floating sections. After permeating the cells with detergent $(0.4 \%$ Triton X-100 in $0.1 \mathrm{M}$ PBS $)$ and blocking unspecific staining with 5\% normal horse serum (Vector Laboratories), sections were sequentially incubated under gentle agitation in primary antibody mouse anti-neuronal nuclei protein (NeuN monoclonal antibody, MAB377, Millipore; dilution, 1:500; $\left.72 \mathrm{~h},+5^{\circ} \mathrm{C}\right)$, secondary antibody (biotinylated anti-mouse $\operatorname{IgG~} \mathrm{H}+\mathrm{L}$, Vector Laboratories; dilution 1:200; for $2 \mathrm{~h}$ at room temperature) and $\mathrm{ABC}$ (Vector Laboratories) in $0.1 \mathrm{M}$ PBS. The reaction product was visualized using $0.4 \mathrm{~mm}$ $\mathrm{DAB}$ and $9.14 \mathrm{~mm}_{2} \mathrm{O}_{2}$ in $0.1 \mathrm{M} \mathrm{PB}$. The sections were mounted on slides, dehydrated, cleared, and coverslipped with QPath Coverquick 2000 (VWR International).

Unbiased stereological estimation of the number of neurons and volumes of cortical layers were performed using the optical fractionator probe implemented with StereoInvestigator software (version 13, MBF Bioscience). Parameters for stereological estimation were adjusted to obtain a coefficient of error of $<0.05$ (Gundersen et al., 1988). We performed a nonparametric Mann-Whitney test for the comparison of cell densities across layers, since these were not normally distributed (ShapiroWilk test: $W=0.95, p<0.05)$.

\section{Results}

\section{Responses of MGBv neurons to tones and complex tones}

The position of the MGBv was identified based on the response of units to pure tones and the final position of the recording probe in each animal (Fig. 1). Ninety-four units were assigned to MGBv, of which 68 were recorded in the animals used exclusively for electrophysiology (Table 1). Eighty-four per cent of the MGBv units had sharply tuned FRAs (median Q10, 1.3; 25th to 75th percentile range, $0.5-5.8$; Fig. $1 E$ ), a median threshold of 40 $\mathrm{dB}$ SPL (25th to 75 th percentile range, 40-60 dB SPL), and CFs ranging from $180 \mathrm{~Hz}$ to $9.2 \mathrm{kHz}$. Edeline et al. (1999) found a similar mean threshold of $38 \pm 3.1 \mathrm{~dB}$ SPL for tones in the MGBv of guinea pigs, while Rodrigues-Dagaeff et al. (1989) reported a threshold range from 30 to $60 \mathrm{~dB}$ SPL in cats. Sharper tuning has been observed in guinea pigs (Q10, $2.60 \pm 0.25$; Edeline et al., $1999)$ and in squirrel monkeys $(0.76 \pm 0.85$ at $<8 \mathrm{kHz}$ and $3.42 \pm$ $2.92>8 \mathrm{kHz}$; Allon et al., 1981). However, the Q10 range that we observed largely overlapped that found by Bizley et al. (2005) for neurons recorded in primary areas of ferret auditory cortex. A further $26 \mathrm{MGBv}$ units were recorded in five animals during characterization of the microbead injection sites (recovery surgeries; Table 1) using a reduced number of sound frequency/level combinations (see Materials and Methods).

In both sets of recordings, response latencies to pure tones were short (Fig. 1F; minimum latency, median $10 \mathrm{~ms}$; interquartile range, 7-14 ms; median peak latency, $19 \mathrm{~ms}$; interquartile range, 14-25 ms) with no differences between them (Wilcoxon rank sum test: minimum latency, $p=0.08$; peak latency, $p=0.10)$.

The CFs of units in different recording locations varied systematically with depth in the MGBv, with a tonotopic gradient from high to low frequency along both the anterior-posterior and dorsoventral dimensions of the MGBv. The tonotopicity revealed in these recordings is consistent with the topography of the A1-MGBv projection in ferrets (Nodal et al., 2006) and is similar to that previously described in the cat MGBv (Calford and Webster, 1981; Lee and Winer, 2008).

Harmonic and mistuned complex tones were presented to $\mathrm{MGBv}$ neurons using the same stimuli (reference and target tones, respectively) that were used in the mistuning detection behavioral task. A typical example of an MGBv unit (CF, $1.2 \mathrm{kHz}$ ) response is shown in Figure $2 A-F$. This unit produced a sustained increase in firing in response to a $400 \mathrm{~Hz} F_{0} \mathrm{HCT}$ (Fig. 2A,C). When the fourth harmonic was shifted to a higher frequency (by $12 \%, 192 \mathrm{~Hz}$ ), the firing rate increased and a distinctive temporal response pattern was observed (Fig. $2 B, D$ ).

Temporal modulation in the responses was analyzed using the SI (Young and Sachs, 1979). The lack of any temporal structure in the PSTH elicited by the HCT (Fig. $2 A, C$ ) was confirmed by a flat plot of the SI versus frequency (Fig. $2 E$ ). In contrast, when the fourth harmonic of the HCT was shifted, the temporal regularity observed in the PSTH for this unit (Fig. $2 B, D$ ) was associated with SI peaks at 16, 192, 208, and $400 \mathrm{~Hz}$ (Fig. $2 F$ ). The peak at $400 \mathrm{~Hz}$ corresponds to the $F_{0}$ of the HCT, whereas the other peaks likely reflect interactions between different frequencies in the stimulus. Thus, the peak at $208 \mathrm{~Hz}$ corresponds to the frequency of the beat produced by the mistuned and next highest harmonic $(2000-1792=208 \mathrm{~Hz})$. The peak at $192 \mathrm{~Hz}$ is the difference in frequency between the $F_{0}$ and the first beat $(400-208=192 \mathrm{~Hz})$, and $16 \mathrm{~Hz}$ is the envelope periodicity and may result from an interaction between the first and second beat frequencies (208$192=16 \mathrm{~Hz}$ ). Similar periodicities have been reported in the chinchilla IC in response to complex tones with a mistuned harmonic (Sinex et al., 2002, 2005).

When the responses of MGBv units to complex tones were analyzed at a population level, the firing rate was found to increase when the frequency of the mistuned harmonic was close to unit CF (Spearman's rank correlation coefficient: $r_{s}=-0.1, p=$ $0.007)$. We further analyzed the units for which the frequency of the mistuned harmonic fell within their respective FRA bandwidths at $30 \mathrm{~dB}$ above threshold. The change in firing rate of these units was significantly different from those units where the frequency of the mistuned harmonic fell outside this bandwidth (two-tailed unpaired $t$ test: $p=7.3 \times 10^{-4}$ ). Furthermore, mistuning was identified as a factor in the increase in firing rates (Fig. $2 G$; repeated-measures ANOVA: $\left.F_{(5,290)}=7.4, p=8.2 \times 10^{-5}\right)$, with significant differences between the responses to the HCTs and MCTs (Scheffé's test, $p<0.05$ ), but not between MCTs with different degrees of mistuning.

These results indicate that neuronal responses in the MGBv are sensitive to mistuning in complex tones, suggesting that the thalamus could be part of the circuitry involved in the detection of harmonicity in complex tones.

\section{Impairment in mistuning detection after selective elimination of A1-MGBv feedback}

We next investigated the role of corticothalamic feedback in mistuning detection. Eight adult ferrets were trained on a mistuning detection task using a go/no-go paradigm (Fig. 3) and subsequently subdivided into two groups, control $(n=5)$ and experimental $(n=3)$. Once experimental animals (hereafter referred to as the corticothalamic lesion group) were trained on this task, bilateral injections of fluorescent microbeads conjugated with chlorin $e_{6}$ were made in the MGBv. Following a survival period of $>6$ weeks, retrogradely labeled cells in A1 layer VI were ablated by illuminating the auditory cortex on both sides with nearinfrared laser light (Fig. 3D-F). The control group comprised three different types of controls $(n=5$; Table 2$)$. Two animals received bilateral injections of active conjugated microbeads in brain areas adjacent to but without encroaching on the MGBv. A further two cases received bilateral injections of inactive microbeads. Finally, one animal received bilateral injections of PBS 


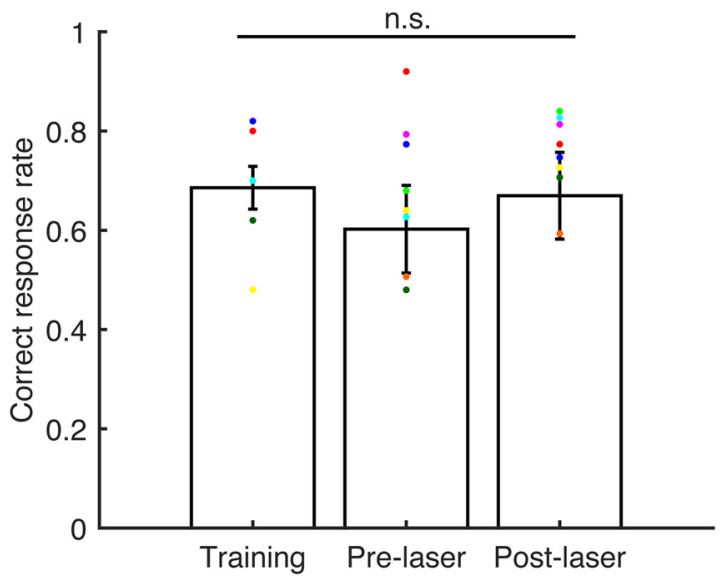

Figure 4. Surgical procedures did not affect the ability of the animals to perform the go/ no-go task. Proportion of correct trials when animals had to discriminate MCTs from HCTs with a level difference $(<10 \mathrm{~dB})$ between the reference and target tones during the initial training, after injection of microbeads but before laser treatment (Pre-laser), and following laser treatment (Post-laser). Bars represent mean values ( \pm SEM). Colored dots represent individual animals. No difference in performance was found for either the lesion or control group (two-way ANOVA: groups, $F_{(1,17)}=1.2, p=0.3 ;$ time, $F_{(2,17)}=0.5, p=0.6$; interaction, $F_{(2,17)}=0.9$, $p=0.4)$.

in MGBv. Subsequent bilateral laser illumination of auditory cortex was performed in all cases as in the experimental group.

To ensure that they were still able to perform the task following the surgical procedures, but without providing further training using near-threshold stimuli, the animals underwent a period of procedural refreshing ( $\sim 2$ weeks) in which an MCT with the maximum mistuning was used as the target stimulus, reinforced by a level difference between reference and target tones (for details, see training methods). Comparing the performances of the ferrets during these procedural refreshing periods revealed no difference in correct response rates between the lesion and control groups or at different stages of the experiment (training, postmicrobead injections but pre-laser, and post-laser; two-way ANOVA: groups, $F_{(1,17)}=1.2, p=0.3$; time point, $F_{(2,17)}=0.5$, $p=0.6$; interaction, $F_{(2,17)}=0.9, p=0.4$; Fig. 4).

Psychometric functions for each animal were obtained, and the $d^{\prime}$ value was plotted as a function of mistuning (Fig. 5). In control animals, the thresholds did not change between pre-laser and postlaser periods or changes were minimal $( \pm 0.2 \mathrm{~Hz}$; bootstrap tests, $p>$ 0.05 ), except for a single case (F1433) in which a lower threshold was obtained post-laser $(-0.4 \mathrm{~Hz})$. In addition, small increases in $d^{\prime}$ values above threshold were observed (Fig. 5A). The overall sensitivity to MCTs in controls, indicated by the difference of the AUC of the psychometric functions between pre-laser and post-laser periods, did not change in three of the five cases (Fig. 5D; bootstrap tests, $p>$ 0.05 ). When a change was observed (two cases), this was indicative of an increase in sensitivity (Fig. 5D). Thus, the mistuning detection ability of the control animals was consistent between pre-laser and post-laser periods, other than a modest improvement in performance in some animals that was presumably training related.

In lesion animals, the thresholds increased (mean \pm SEM threshold difference, $5.8 \pm 2.3 \mathrm{~Hz}$ ) and sensitivity decreased (AUC difference, $-3.1 \pm 0.3$ ) after lesioning of corticothalamic neurons, with the psychometric functions shifted toward higher mistuning values (rightward shift, Fig. 5B). In two of the lesion cases (F1205 and F1430), the threshold increased from $7.8 \mathrm{~Hz}$ (pre-laser) to $17.8 \mathrm{~Hz}$ (post-laser) and from $0.9 \mathrm{~Hz}$ (pre-laser) to $2.9 \mathrm{~Hz}$ (post-laser), respectively (bootstrap test, $p<0.05$ ). In a third case (F1209), the threshold increased from $7.8 \mathrm{~Hz}$ (pre-laser) to $13.5 \mathrm{~Hz}$ (post-laser), although this difference did not reach significance (bootstrap test, $p>0.05)$. The AUC differences between the pre-laser and post-laser periods decreased significantly for all of the animals in the lesion group (bootstrap tests, $p<0.05$; Fig. $5 D$ ), suggesting that their mistuning detection ability had been impaired following the loss of corticothalamic neurons.

These effects were also apparent when we compared the performances of the control and lesion animals. Thus, the threshold change between pre-laser and post-laser periods was significantly larger for the lesion group than the control group (two-tailed unpaired $t$ test, $p=0.01$; Fig. $5 C$ ). Similarly, the AUC difference in $d^{\prime}$ values across all mistuning values between pre-laser and post-laser periods differed significantly (mean difference \pm SEM: control group, $2.0 \pm 0.7$; lesion group, $-3.1 \pm 0.3$; two-tailed unpaired $t$ test, $p=0.002$; Fig. 5D).

Response bias was estimated by plotting $\lambda_{\text {center }}$ values against the degree of mistuning $(0.1-192 \mathrm{~Hz})$ and calculating the slope of the regression line. The slope values tended to be negative for pre-laser and post-laser periods in both groups, indicating a small bias to make "go" responses (Fig. $5 E$ ). No differences in slope values were found between pre-laser and post-laser periods in either control or lesion groups (slope comparison ANOVA, $p=$ 0.1 and 0.9 , respectively). Therefore, the mistuning detection impairment exhibited by the corticothalamic lesion group was not due to changes in the decision criteria of the animals.

\section{Corticothalamic cell loss was observed in animals with impaired mistuning detection}

Histological analysis was conducted once animals completed the behavioral testing. The injection sites were identified by the presence of fluorescence (neurons or aggregates of multiple neurons that could not always be individually resolved) that contained the injected microbeads (Fig. 3E; Table 2). In lesion cases, the injection sites were mainly restricted to the MGBv, although in one case (F1209, right side) the injection was centered in the dorsal division of the MGB but was spread dorsally in the LGN and ventrally in the $\mathrm{MGBv}$. As expected for MGBv injections, retrogradely labeled fluorescent neurons were always observed in the ipsilateral IC, mainly in its central nucleus. Loss of corticothalamic cells by chromophoretargeted laser photolysis was evaluated using the following two different metrics: by calculating the proportion of fluorescent retrogradely labeled cells in the auditory cortex, and by estimating the neuronal density in each layer of the cortex.

The number of retrogradely labeled fluorescent cells in the three main regions of the auditory cortex, the MEG (where A1 is located), posterior ectosylvian gyrus (PEG), and anterior ectosylvian gyrus (AEG), was counted in the lesion animals, and the proportion of cells labeled in each region relative to the total labeled cells in the ectosylvian gyrus was calculated (Fig. 6A). These values were then compared with reference values for the ferret A1-MGBv corticothalamic projection obtained from an additional animal used as an anatomical control (F0416), in which a BDA injection was made in the center of the MGBv. In this control case, $85 \%$ of the labeled neurons were found in the MEG, $15 \%$ in the PEG, and none in the AEG (Fig. 6A, dotted line).

All three lesion animals (F1205, F1209, and F1430) had a lower proportion of labeled cells in the MEG than the anatomical control (F0416), suggesting a loss of A1-MGBv projection neurons due to chromophore-targeted laser photolysis (Fig. 6A). In addition and contrary to the control case, PEG and AEG, where higher-level auditory cortical fields are located, contained a higher proportion of labeled cells than MEG following five of six 
Control

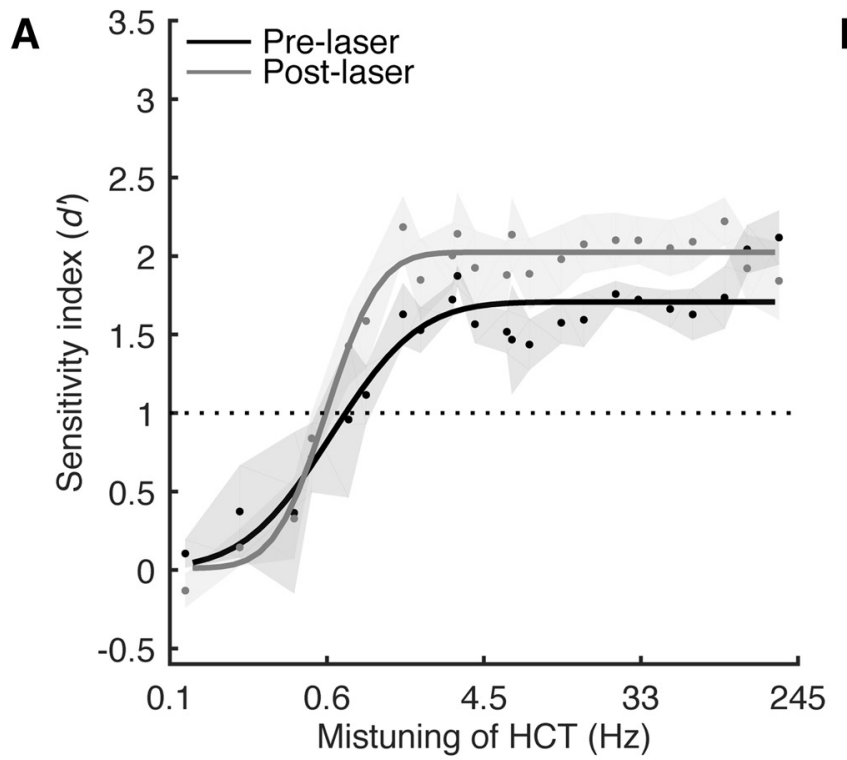

\section{Lesion}

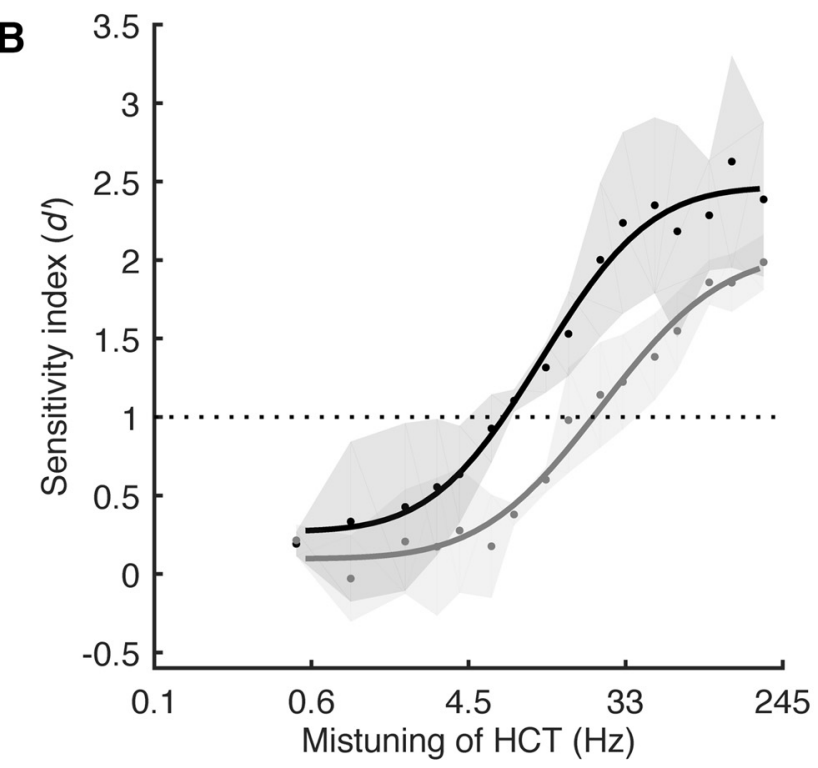

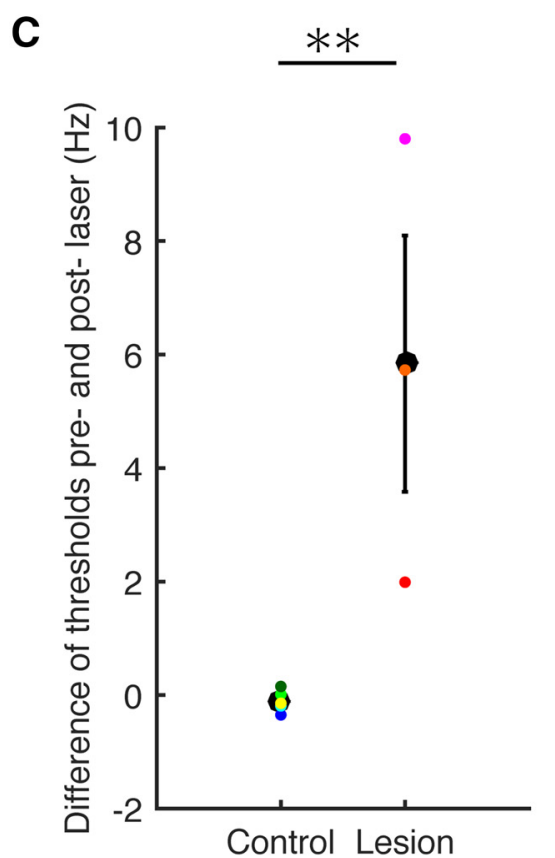
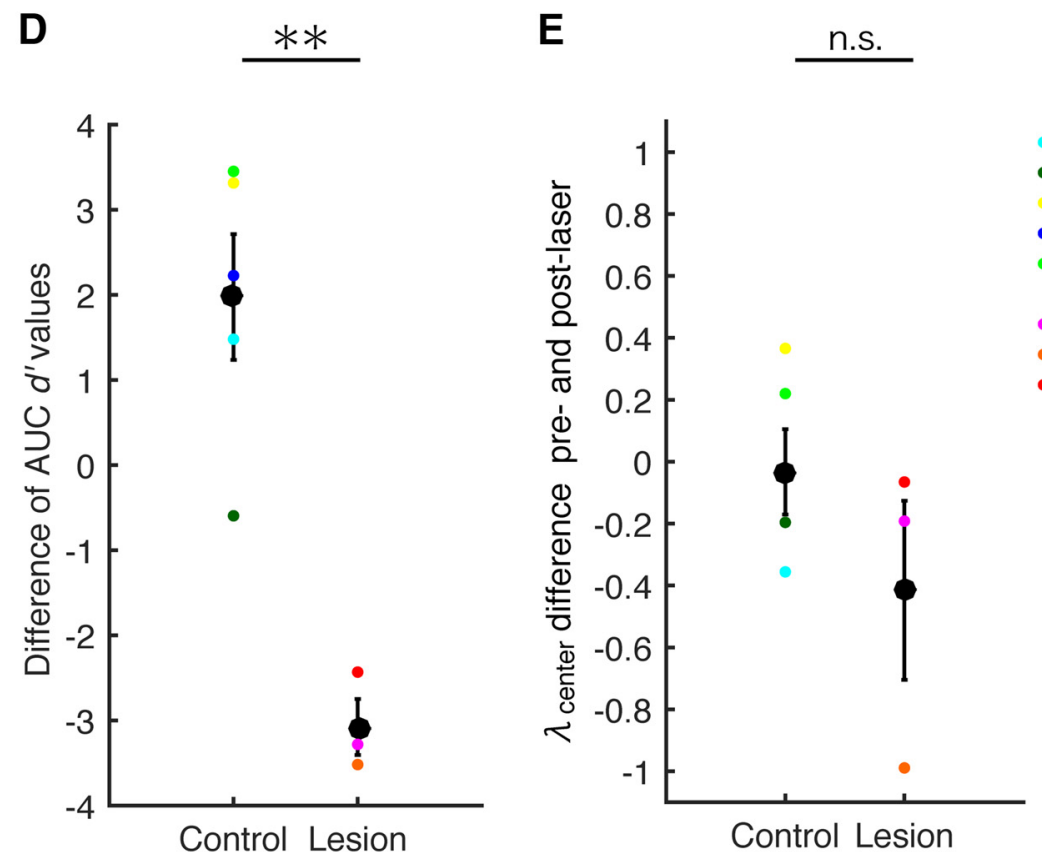

Figure 5. Corticothalamic lesions impaired mistuning detection performance. $\boldsymbol{A}, \boldsymbol{B}$, Mean $d^{\prime}( \pm \mathrm{SEM})$ values derived from the hit and false alarm rates of the control $(\boldsymbol{A} ; n=5)$ and lesion $(\boldsymbol{B} ; n=3)$ groups are plotted against the degree of mistuning (on a log scale) of a single-frequency component of an HCT. For each group, data are shown before laser illumination (pre-laser period, black) and $>3$ weeks after (post-laser period, gray). A cumulative Gaussian distribution was used to fit the psychometric functions (lines). Dots represent mean values across animals, and the shaded areas represent the SEM. The horizontal dashed lines indicate the threshold criterion of $d^{\prime}=1$. C $-\boldsymbol{E}$, Differences (mean \pm SEM) between pre-laser and post-laser performance were computed for threshold $(\boldsymbol{C})$, the AUC of the psychometric functions $(\boldsymbol{D})$, and $\lambda_{\text {center }}$ values $(\boldsymbol{E})$. Colored dots represent data from individual animals. Significant differences between the control and lesion groups are indicated above the panels: ${ }^{* *} p<0.01$. n.S., Not significant.

MGB injections (Fig. 6A). This again suggests that retrogradely labeled neurons were principally lost from A1, the region of auditory cortex that targets MGBv. Only on the right side of F1209 was the proportion of labeling higher in MEG and more like the control, which is consistent with the injection site in this case being located dorsal to the MGBv.

Examination and stereological quantification of NeuNimmunostained sections of the auditory cortex at the level of the MEG revealed a significant reduction in the density in layer VI neurons in the lesion animals relative to the controls (MannWhitney test: $\left.U_{(6,4)}=24, p=0.005\right)$. However, comparison of cell density across other layers did not show any significant differences between lesion and control animals (layer I: $U_{(6,4)}=13$, $p=0.5$; layer II/III: $U_{(6,4)}=19, p=0.09$; layer IV: $U_{(6,4)}=19, p=$ 0.09 ; layer $\left.\mathrm{V}: U_{(6,4)}=20, p=0.06\right)$, confirming that the loss of corticothalamic neurons was restricted to layer VI.

We further explored whether there were any changes in layer VI neuron density across groups and cortical regions (Figs. 6B, C, 
7). Stereological quantification of neurons in layer VI across animals demonstrated that the corticothalamic lesion animals had a reduced neuronal density in MEG relative to PEG and AEG, and also to the values seen in control animals (Figs. $6 B, 7 B)$. These differences were statistically significant between lesion and control groups and between cortical regions, but not between left and right hemispheres (repeated-measures ANOVA: cortical regions, $F_{(2,6)}=8.9, p=0.016$; cortical region $\times$ group, $F_{(2,6)}=11.4$, $p=0.009$; hemispheres, $F_{(1,3)}=8.1, p=$ 0.07 , hemispheres $\times$ group, $F_{(1,3)}=5.3$, $p=0.1)$.

No difference in neuronal density in the three regions of auditory cortex were found in the control group, and there were no differences in the values obtained for PEG between lesion and control groups. Therefore, cell densities in AEG and MEG were normalized by the values of PEG to evaluate cell loss (Fig. 6C). The proportion for MEG in the lesion group was reduced by $27 \pm 4 \%$ (mean \pm SEM) compared with the control group (Tukey-Kramer test, $p<0.01$ ), suggesting that $\sim 30 \%$ of cortical neurons were eliminated by chromophore-targeted laser photolysis.

Collectively, our results show that chromophore-targeted laser photolysis produced selective elimination of layer VI cells in A1 that project to the MGBv, without affecting the number of neurons in the non-primary auditory cortical regions (AEG and PEG).

\section{Discussion}

The present study examined the behavioral consequences of selective lesioning by chromophore-targeted laser photolysis the descending projection from the auditory cortex to the thalamus. We found that the loss of retrogradely labeled corticothalamic layer VI pyramidal neurons that project to the MGBv impaired the ability of ferrets to detect a single mistuned harmonic in an HCT, a measure of sensitivity to the harmonic structure of sounds. Their performance was unaffected, however, on an easier version of the task in which level cues were additionally available for discriminating MCTs from HCTs. These results highlight the importance of the core thalamus (MGBv) in processing complex tones and suggest that corticothalamic feedback contributes to harmonicity detection and, therefore, potentially to auditory scene analysis.

\section{Responses to complex tones in MGBv}

We identified the position of the auditory thalamus by stereotaxic-guided electrophysiology (see also Garcia-Lazaro et al., 2011) and confirmed this by histological reconstruction of recording sites. Response properties of the ferret auditory thalamus were consistent with previous studies in other mammalian species (Allon et al., 1981; Calford, 1983; Rodrigues-Dagaeff et al., 1989; Rouiller et al., 1989; Redies and Brandner, 1991; Bordi and LeDoux, 1994; Edeline et al., 1999; Anderson et al., 2007; Wallace et al., 2007).
B

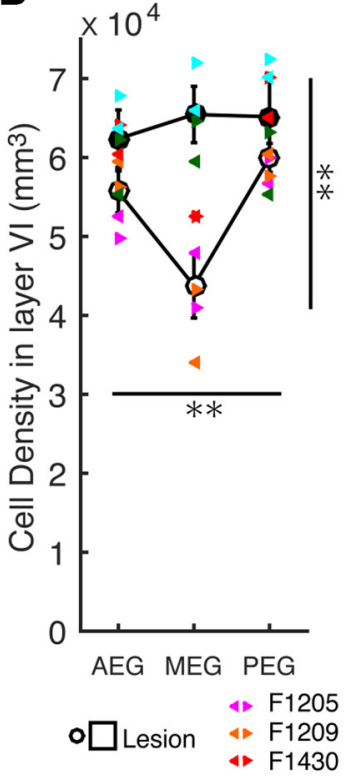

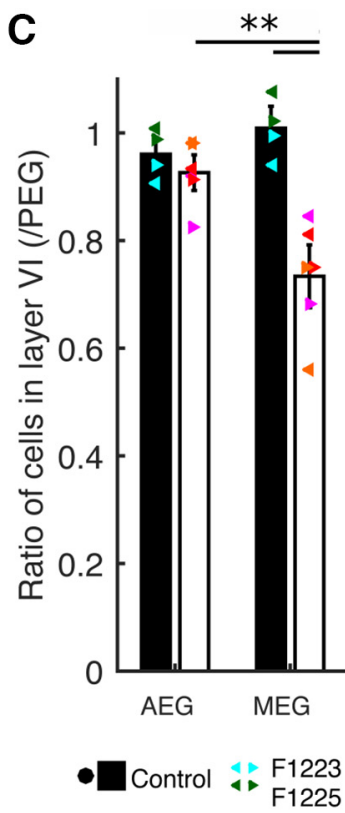

Figure 6. Corticothalamic cell loss after chromophore-targeted laser photolysis in the A1-MGBv pathway. A, The ratio of labeled cells in MEG (where A1 is located), PEG and AEG relative to the total number of labeled cells in the ectosylvian gyrus. White circles mean in the lesion animals. Black triangles represent values obtained from an anatomical control case in which BDA the left and right hemispheres, respectively. $\boldsymbol{B}$, Cell density values in layer VI of MEG, PEG, and AEG. Black circles represent the mean $p=0.016$; region $\times$ group, $\left.F_{(2,6)}=11.4, p=0.009\right)$. C, Histograms of cell density ratio in MEG and AEG (relative to PEG; mean \pm SEM) showed significantly lower cell density in the MEG in the lesion group than in the control group (Tukey-Kramer test, ${ }^{* *} p<0.01$ ).

MGBv neurons responded to MCTs with specific temporal response patterns. Phase locking corresponding to the periodicities of MCTs has also been reported for neurons recorded in the cochlear nucleus, IC, and A1 (Sinex et al., 2002, 2005; Sinex, 2008; Fishman and Steinschneider, 2010). Furthermore, we found that firing rate in response to MCTs is higher than that in response to HCTs in MGBv neurons when their CFs were close to the frequency of the mistuned harmonic, which is in agreement with findings in primate auditory cortex (Fishman and Steinschneider, 2010).

\section{Selective elimination of corticothalamic neurons}

Chromophore-targeted laser photolysis is a powerful technique for selectively eliminating a targeted population of neurons without damaging other nontargeted neurons, glia, or axons of passage at a particular brain site (Macklis, 1993; Magavi et al., 2000). Following injections of fluorescent microbeads conjugated with chlorin $e_{6}$ into the ferret IC, nonlabeled neurons in other cortical layers are preserved when the infrared laser light is focused at the layer containing the labeled neurons (Bajo et al., 2010). The amount of laser-induced corticothalamic cell loss observed in the present study was comparable to that in previous reports (Eyding et al., 2003; Bajo et al., 2010), with 30\% of cells reported to be eliminated in layer VI of the primary visual cortex (V1; Eyding et al., 2003) and $27 \pm 4 \%$ in the present study.

In cats, corticothalamic cells make up $\sim 50 \%$ of neurons in layer VI of A1 (Prieto and Winer, 1999) and V1 (McCourt et al., 1986; Eyding et al., 2003). Consequently, a 30\% loss of neurons in V1 following chromophore-targeted laser photolysis corresponds to $\sim 60 \%$ loss of visual corticothalamic neurons (Eyding et al., 2003). If the proportion of corticothalamic cells in layer VI 

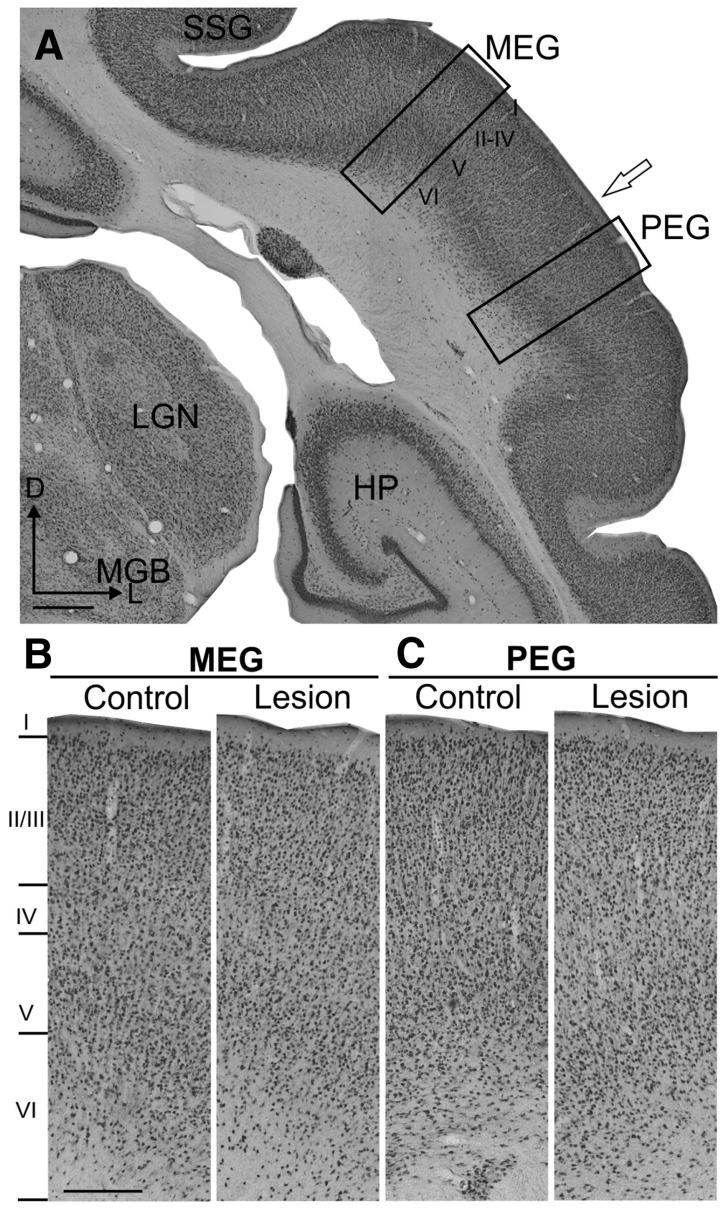

Figure 7. Neuronal density in layer VI of MEG is lower in animals with corticothalamic lesions than in controls. $A$, Coronal section immunostained with NeuN at the level of the auditory cortex (control case). Rectangles indicate the regions of MEG (where A1 is located) and PEG shown at higher magnification in $\boldsymbol{B}$ and $\boldsymbol{C}$. The open arrow indicates the border between MEG and PEG. $\boldsymbol{B}$, NeuN cell density in MEG layer VI of the lesion example is lower than in the control (for quantification, see Fig. 6). $C$, No difference in cell density in layer VI of the PEG was found between control and lesion cases. Scale bars: $\boldsymbol{A}, 1 \mathrm{~mm} ; \boldsymbol{B}, 250 \mu \mathrm{m}$. I-VI, layers $1-6$ of the cortex.

is the same as in ferret $\mathrm{A} 1$, this too would indicate an $\sim 60 \%$ reduction in the number of neurons with descending inputs to the MGBv. This value is close to the previously reported corticocollicular cell loss in ferret A1 using the same approach, which was sufficient to generate a learning deficit in a sound localization task (Bajo et al., 2010).

Although the corticothalamic lesions in our study produced significantly raised mistuning detection thresholds, the animals were still able to perform the task. This may reflect the contribution of intact corticothalamic neurons, as well as other circuits in the auditory system and potential compensatory plasticity.

\section{Behavioral performance and effect of learning}

We measured mistuning detection using a go/no-go design, which has previously been used to show that the threshold for mistuning detecting in ferrets $(0.8 \pm 0.1 \mathrm{~Hz}$; Homma et al., 2016) is comparable to that reported for other animal species (Lohr and Dooling, 1998; Klinge and Klump, 2009, 2010) and is superior to that measured in humans (Moore et al., 1985; Hartmann et al., 1990; Lohr and Dooling, 1998; Klinge and Klump, 2009). The present study was based on a longitudinal comparison over the course of many months of the performance of individual animals before and after corticothalamic lesion (lesion group) or sham treatment (control group). Importantly, the ability of ferrets to discriminate complex tones on the basis of intensity difference cues was preserved following surgical interventions in both the lesion and control group. Also, control ferrets did not show any impairment in mistuning sensitivity following the sham operations, suggesting that the surgical interventions per se did not affect the behavior of the animals.

The control animals exhibited improved sensitivity for detecting a mistuned harmonic between pre-laser and post-laser periods, although their thresholds remained unchanged. Training-induced changes in A1 response properties have been linked to learning improvements in a number of studies (Kilgard and Merzenich, 1998; Bao et al., 2004; Weinberger, 2004; Ohl and Scheich, 2005; Polley et al., 2006; Schnupp et al., 2006). Hence, it seems likely that neuronal sensitivity to mistuning would have improved in control ferrets over the course of training. In contrast, animals with corticothalamic lesions did not show improved performance over the training procedure but rather a shift of psychometric functions in a direction consistent with impaired mistuning detection and significantly higher thresholds. Therefore, the A1-MGBv feedback pathway appears to be important for the sensitivity of ferrets to the harmonic structure of sounds.

\section{Corticothalamic feedback and complex sound perception}

Corticothalamic feedback from infragranular pyramidal neurons in layers V and VI has a predominantly fast driving or modulatory influence on subcortical neurons, respectively (Ojima, 1994; Zhang and Jones, 2004; Winer et al., 2005). Modulatory layer VI neurons form the majority of the projection from A1 to lemniscal thalamus (Nodal et al., 2006; Llano and Sherman, 2008). Consequently, A1 feedback can influence the properties of MGBv neurons by affecting their overall excitability, receptive field tuning (Zhang and Yan, 2008; Luo et al., 2011), and firing patterns (Ryugo and Weinberger, 1976; Orman and Humphrey, 1981; Villa et al., 1991; He, 1997; He et al., 2002; Yu et al., 2004).

The changes induced by corticofugal feedback in the response properties of neurons in the thalamus and at lower levels of the pathway are thought to be involved in mediating the effects of experience on auditory processing, in turn modifying the information delivered to the cortex (Suga and Ma, 2003; Zhang and Yan, 2008). Although modulation of response properties by corticothalamic feedback has been studied extensively across different sensory modalities (Ghazanfar et al., 2001, Temereanca and Simons, 2004; Andolina et al., 2007; 2013; Wang et al., 2016), the behavioral impact of this top-down circuitry is only now becoming understood (PaisVieira et al., 2013; Happel et al., 2014). For example, it has recently been demonstrated that recurrent corticothalamic feedback in rodents promotes the detection of behaviorally important stimuli via a gain modulation of task-relevant information at the level of the auditory cortex (Happel et al., 2014).

Auditory cortical ablations in other species do not impair tone frequency discrimination (Ohl et al., 1999; Ono et al., 2006) but do produce a persistent impairment in the ability of animals to discriminate more spectrotemporally complex auditory stimuli (Rybalko et al., 2006; Wetzel et al., 2008). Consequently, it is unlikely that the raised mistuning detection thresholds produced in the present study by a more selective loss of corticothalamic feedback can be attributed to an effect on tone discrimination. Our results therefore provide the first behavioral evidence that corticothalamic feedback contributes to the perception of complex sounds.

Detection of mistuned harmonics within an HCT may be based on sensitivity to the spatial pattern of excitation or tempo- 
ral cues (Goldstein, 1973; Houtsma and Smurzynski, 1990; Meddis and Hewitt, 1991a,b), with some evidence suggesting that temporal processing may be more important in nonhuman species (Klinge et al., 2010). In keeping with this, we showed that MGBv neurons in ferrets represent the temporal periodicity of MCTs, suggesting that corticothalamic feedback might be responsible for enhancing temporal precision in the tonic firing patterns of these neurons. While recording from $\mathrm{MGBv}$ neurons during a mistuning detection task would be required to confirm these, cortical electrical stimulation or focal inactivation has been shown to shape the temporal response properties of subcortical neurons (for review, see Suga and Ma, 2003). If changes in temporal response properties during behavior are mediated by corticothalamic feedback, this descending projection may also contribute to other tasks that rely on sensitivity to temporal fluctuations, including the segregation of sounds from background noise (Nelken et al., 1999; Las et al., 2005).

It has been particularly difficult to identify the role of corticothalamic modulation in the perception of auditory or other sensory stimuli. By showing that elimination of much of the A1-MGBv pathway degrades the ability of ferrets to perceive the harmonic structure of complex tones, our results suggest that this hitherto poorly understood descending pathway may play a critical role in auditory scene analysis.

\section{References}

Allon N, Yeshurun Y, Wollberg Z (1981) Responses of single cells in the medial geniculate body of awake squirrel monkeys. Exp Brain Res 41:222232. Medline

Anderson LA, Wallace MN, Palmer AR (2007) Identification of subdivisions in the medial geniculate body of the guinea pig. Hear Res 228:156167. CrossRef Medline

Andolina IM, Jones HE, Wang W, Sillito AM (2007) Corticothalamic feedback enhances stimulus response precision in the visual system. Proc Natl Acad Sci U S A 104:1685-1690. CrossRef Medline

Andolina IM, Jones HE, Sillito AM (2013) Effects of cortical feedback on the spatial properties of relay cells in the lateral geniculate nucleus. J Neurophysiol 109:889-899. CrossRef Medline

Bajo VM, Rouiller EM, Welker E, Clarke S, Villa AE, de Ribaupierre Y, de Ribaupierre F (1995) Morphology and spatial distribution of corticothalamic terminals originating from the cat auditory cortex. Hear Res 83:161-174. CrossRef Medline

Bajo VM, Nodal FR, Moore DR, King AJ (2010) The descending corticocollicular pathway mediates learning-induced auditory plasticity. Nat Neurosci 13:253-260. CrossRef Medline

Bao S, Chang EF, Woods J, Merzenich MM (2004) Temporal plasticity in the primary auditory cortex induced by operant perceptual learning. Nat Neurosci 7:974-981. CrossRef Medline

Barth DS, MacDonald KD (1996) Thalamic modulation of high-frequency oscillating potentials in auditory cortex. Nature 383:78-81. CrossRef Medline

Bartlett EL, Wang X (2007) Neural representations of temporally modulated signals in the auditory thalamus of awake primates. J Neurophysiol 97:1005-1017. CrossRef Medline

Bizley JK, Nodal FR, Nelken I, King AJ (2005) Functional organization of ferret auditory cortex. Cereb Cortex 15:1637-1653. CrossRef Medline

Bordi F, LeDoux JE (1994) Response properties of single units in areas of rat auditory thalamus that project to the amygdala-II. Cells receiving convergent auditory and somatosensory inputs and cells antidromically activated by amygdala stimulation. Exp Brain Res 98:275-286. CrossRef Medline

Calford MB (1983) The parcellation of the medial geniculate body of the cat defined by the auditory response properties of single units. J Neurosci 3:2350-2364. Medline

Calford MB, Webster WR (1981) Auditory representation within principal division of cat medial geniculate body: an electrophysiology study. J Neurophysiol 45:1013-1028. Medline

de Cheveigné A, McAdams S, Marin CMH (1997) Concurrent vowel iden- tification. II. Effects of phase, harmonicity, and task. J Acoust Soc Am 101:2848-2856. CrossRef

Edeline JM, Manunta Y, Nodal FR, Bajo VM (1999) Do auditory responses recorded from awake animals reflect the anatomical parcellation of the auditory thalamus? Hear Res 131:135-152. CrossRef Medline

Eyding D, Macklis JD, Neubacher U, Funke K, Wörgötter F (2003) Selective elimination of corticogeniculate feedback abolishes the electroencephalogram dependence of primary visual cortical receptive fields and reduces their spatial specificity. J Neurosci 23:7021-7033. Medline

Fishman YI, Steinschneider M (2010) Neural correlates of auditory scene analysis based on inharmonicity in monkey primary auditory cortex. J Neurosci 30:12480-12494. CrossRef Medline

Garcia-Lazaro JA, Ahmed B, Schnupp JW (2011) Emergence of tuning to natural stimulus statistics along the central auditory pathway. PLoS One 6:e22584. CrossRef Medline

Ghazanfar AA, Krupa DJ, Nicolelis MA (2001) Role of cortical feedback in the receptive field structure and nonlinear response properties of somatosensory thalamic neurons. Exp Brain Res 141:88-100. CrossRef Medline

Goldstein JL (1973) An optimum processor theory for the central formation of the pitch of complex tones. J Acoust Soc Am 54:1496-1516. CrossRef Medline

Gundersen HJ, Bagger P, Bendtsen TF, Evans SM, Korbo L, Marcussen N, Møller A, Nielsen K, Nyengaard JR, Pakkenberg B (1988) The new stereological tools: disector, fractionator, nucleator and point sampled intercepts and their use in pathological research and diagnosis. APMIS 96:857-881. CrossRef Medline

Happel MF, Deliano M, Handschuh J, Ohl FW (2014) Dopaminemodulated recurrent corticoefferent feedback in primary sensory cortex promotes detection of behaviorally relevant stimuli. J Neurosci 34:12341247. CrossRef Medline

Hartmann WM, McAdams S, Smith BK (1990) Hearing a mistuned harmonic in an otherwise periodic complex tone. J Acoust Soc Am 88:17121724. CrossRef Medline

He J (1997) Modulatory effects of regional cortical activation on the onset responses of the cat medial geniculate neurons. J Neurophysiol 77:896908. Medline

He J, Yu YQ, Xiong Y, Hashikawa T, Chan YS (2002) Modulatory effect of cortical activation on the lemniscal auditory thalamus of the Guinea pig. J Neurophysiol 88:1040-1050. Medline

Homma NY, Bajo VM, Happel MF, Nodal FR, King AJ (2016) Mistuning detection performance of ferrets in a go/no-go task. J Acoust Soc Am 139:EL246. CrossRef Medline

Houtsma AJM, Smurzynski J (1990) Pitch identification and discrimination for complex tones with many harmonics. J Acoust Soc Am 87:304-310. CrossRef

Jaramillo S, Zador AM (2011) The auditory cortex mediates the perceptual effects of acoustic temporal expectation. Nat Neurosci 14:246-251. CrossRef Medline

Kilgard MP, Merzenich MM (1998) Plasticity of temporal information processing in the primary auditory cortex. Nat Neurosci 1:727-731. CrossRef Medline

Klinge A, Klump GM (2009) Frequency difference limens of pure tones and harmonics within complex stimuli in Mongolian gerbils and humans. J Acoust Soc Am 125:304-314. CrossRef Medline

Klinge A, Klump G (2010) Mistuning detection and onset asynchrony in harmonic complexes in Mongolian gerbils. J Acoust Soc Am 128:280290. CrossRef Medline

Klinge A, Itatani N, Klump GM (2010) A comparative view on the perception of mistuning: constraints of the auditory periphery. In: Neurophysiological bases of auditory perception (Lopez-Poveda EA, Palmer AR, Meddis R, eds), pp 465-475. New York: Springer New York.

Las L, Stern EA, Nelken I (2005) Representation of tone in fluctuating maskers in the ascending auditory system. J Neurosci 25:1503-1513. CrossRef Medline

Lee CC (2013) Thalamic and cortical pathways supporting auditory processing. Brain Lang 126:22-28. CrossRef Medline

Lee CC, Winer JA (2008) Connections of cat auditory cortex: I. Thalamocortical system. J Comp Neurol 507:1879-1900. CrossRef Medline

Llano DA, Sherman SM (2008) Evidence for nonreciprocal organization of the mouse auditory thalamocortical-corticothalamic projection systems. J Comp Neurol 507:1209-1227. CrossRef Medline

Lohr B, Dooling RJ (1998) Detection of changes in timbre and harmonicity 
in complex sounds by zebra finches (Taeniopygia guttata) and budgerigars (Melopsittacus undulatus). J Comp Psychol 112:36-47. CrossRef Medline

Luo F, Liu X, Wang C, Yan J (2011) The pedunculopontine tegmental nucleus: a second cholinergic source for frequency-specific auditory plasticity. J Neurophysiol 105:107-116. CrossRef Medline

Macklis JD (1993) Transplanted neocortical neurons migrate selectively into regions of neuronal degeneration produced by chromophoretargeted laser photolysis. J Neurosci 13:3848-3863. Medline

Magavi SS, Leavitt BR, Macklis JD (2000) Induction of neurogenesis in the neocortex of adult mice. Nature 405:951-955. CrossRef Medline

McCourt ME, Boyapati J, Henry GH (1986) Layering in lamina 6 of cat striate cortex. Brain Res 364:181-185. CrossRef Medline

Meddis R, Hewitt MJ (1991a) Virtual pitch and phase sensitivity of a computer model of the auditory periphery. I: pitch identification. J Acoust Soc Am 89:2866. CrossRef

Meddis R, Hewitt MJ (1991b) Virtual pitch and phase sensitivity of a computer model of the auditory periphery. II: phase sensitivity. J Acoust Soc Am 89:2883. CrossRef

Miller LM, Escabí MA, Read HL, Schreiner CE (2002) Spectrotemporal receptive fields in the lemniscal auditory thalamus and cortex. J Neurophysiol 87:516-527. Medline

Moore BC, Peters RW, Glasberg BR (1985) Thresholds for the detection of inharmonicity in complex tones. J Acoust Soc Am 77:1861-1867. CrossRef Medline

Moshitch D, Las L, Ulanovsky N, Bar-Yosef O, Nelken I (2006) Responses of neurons in primary auditory cortex (A1) to pure tones in the halothaneanesthetized cat. J Neurophysiol 95:3756-3769. CrossRef Medline

Nelken I, Rotman Y, Bar Yosef O (1999) Responses of auditory-cortex neurons to structural features of natural sounds. Nature 397:154-157. CrossRef Medline

Nodal FR, Bajo VM, Bizley JK, King AJ (2006) Cortico-thalamic connectivity of ferret auditory cortex. Abstr Assoc Res Otolaryngol 29:238.

Ohl FW, Scheich H (2005) Learning-induced plasticity in animal and human auditory cortex. Curr Opin Neurobiol 15:470-477. CrossRef Medline

Ohl FW, Wetzel W, Wagner T, Rech A, Scheich H (1999) Bilateral ablation of auditory cortex in Mongolian gerbil affects discrimination of frequency modulated tones but not of pure tones. Learn Mem 6:347-362. Medline

Ojima H (1994) Terminal morphology and distribution of corticothalamic fibers originating from layers 5 and 6 of cat primary auditory cortex. Cereb Cortex 4:646-663. CrossRef Medline

Ono K, Kudoh M, Shibuki K (2006) Roles of the auditory cortex in discrimination learning by rats. Eur J Neurosci 23:1623-1632. CrossRef Medline

Orman SS, Humphrey GL (1981) Effects of changes in cortical arousal and of auditory cortex cooling on neuronal activity in the medial geniculate body. Exp brain Res 42:475-482. Medline

Pais-Vieira M, Lebedev MA, Wiest MC, Nicolelis MA (2013) Simultaneous top-down modulation of the primary somatosensory cortex and thalamic nuclei during active tactile discrimination. J Neurosci 33:4076-4093. CrossRef Medline

Polley DB, Steinberg EE, Merzenich MM (2006) Perceptual learning directs auditory cortical map reorganization through top-down influences. J Neurosci 26:4970-4982. CrossRef Medline

Prieto JJ, Winer J (1999) Layer VI in cat primary auditory cortex: Golgi study and sublaminar origins of projection neurons. J Comp Neurol 404: 332-358. CrossRef Medline

Redies H, Brandner S (1991) Functional organization of the auditory thalamus in the guinea pig. Exp Brain Res 86:384-392. Medline

Rodrigues-Dagaeff C, Simm G, De Ribaupierre Y, Villa A, De Ribaupierre F, Rouiller EM (1989) Functional organization of the ventral division of the medial geniculate body of the cat: evidence for a rostro-caudal gradient of response properties and cortical projections. Hear Res 39:103-125. CrossRef Medline

Rouiller EM, Welker E (1991) Morphology of corticothalamic terminals arising from the auditory cortex of the rat: a Phaseolus vulgarisleucoagglutinin (PHA-L) tracing study. Hear Res 56:179-190. CrossRef Medline

Rouiller EM, Rodrigues-Dagaeff C, Simm G, De Ribaupierre Y, Villa A, De Ribaupierre F (1989) Functional organization of the medial division of the medial geniculate body of the cat: tonotopic organization, spatial distribution of response properties and cortical connections. Hear Res 39:127-142. CrossRef Medline
Rybalko N, Suta D, Nwabueze-Ogbo F, Syka J (2006) Effect of auditory cortex lesions on the discrimination of frequency-modulated tones in rats. Eur J Neurosci 23:1614-1622. CrossRef Medline

Ryugo DK, Weinberger NM (1976) Corticofugal modulation of the medial geniculate body. Exp Neurol 391:377-391.

Schnupp JW, Hall TM, Kokelaar RF, Ahmed B (2006) Plasticity of temporal pattern codes for vocalization stimuli in primary auditory cortex. J Neurosci 26:4785-4795. CrossRef Medline

Sheen VL, Macklis JD (1995) Targeted neocortical cell death in adult mice guides migration and differentiation of transplanted embryonic neurons. J Neurosci 15:8378-8392. Medline

Sherman SM, Guillery RW (2011) Distinct functions for direct and transthalamic corticocortical connections. J Neurophysiol 106:1068-1077. CrossRef Medline

Sinex DG (2008) Responses of cochlear nucleus neurons to harmonic and mistuned complex tones. Hear Res 238:39-48. CrossRef Medline

Sinex DG, Henderson Sabes J, Li H (2002) Responses of inferior colliculus neurons to harmonic and mistuned complex tones. Hear Res 168:150162. CrossRef Medline

Sinex DG, Guzik H, Li H, Henderson Sabes J (2003) Responses of auditory nerve fibers to harmonic and mistuned complex tones. Hear Res 182: 130-139. CrossRef Medline

Sinex DG, Li H, Velenovsky DS (2005) Prevalence of stereotypical responses to mistuned complex tones in the inferior colliculus. J Neurophysiol 94: 3523-3537. CrossRef Medline

Suga N, MaX (2003) Multiparametric corticofugal modulation and plasticity in the auditory system. Nat Rev Neurosci 4:783-794. CrossRef Medline

Sutter ML, Schreiner CE (1991) Physiology and topography of neurons with multipeaked tuning curves in cat primary auditory cortex. J Neurophysiol 65:1207-1226. Medline

Talwar SK, Musial PG, Gerstein GL (2001) Role of mammalian auditory cortex in the perception of elementary sound properties. J Neurophysiol 85:2350-2358. Medline

Temereanca S, Simons DJ (2004) Functional topography of corticothalamic feedback enhances thalamic spatial response tuning in the somatosensory whisker/barrel system. Neuron 41:639-651. CrossRef Medline

Villa AE, Rouiller EM, Simm GM, Zurita P, de Ribaupierre Y, de Ribaupierre F (1991) Corticofugal modulation of the information processing in the auditory thalamus of the cat. Exp Brain Res 86:506-517. CrossRef Medline

Wallace MN, Anderson LA, Palmer AR (2007) Phase-locked responses to pure tones in the auditory thalamus. J Neurophysiol 98:1941-1952. CrossRef Medline

Wang W, Andolina IM, Lu Y, Jones HE, Sillito AM (2016) Focal gain control of thalamic visual receptive fields by layer 6 corticothalamic feedback. Cereb Cortex. Advance online publication. Retrieved May 19, 2017. doi: 10.1093/cercor/bhw376. CrossRef Medline

Weinberger NM (2004) Specific long-term memory traces in primary auditory cortex. Nat Rev Neurosci 5:279-290. CrossRef Medline

Wetzel W, Ohl FW, Scheich H (2008) Global versus local processing of frequency-modulated tones in gerbils: an animal model of lateralized auditory cortex functions. Proc Natl Acad Sci U S A 105:6753-6758. CrossRef Medline

Wickens T (2002) Elementary signal detection theory. New York: Oxford UP.

Winer JA, Miller LM, Lee CC, Schreiner CE (2005) Auditory thalamocortical transformation: structure and function. Trends Neurosci 28: 255-263. CrossRef Medline

Young ED, Sachs MB (1979) Representation of steady-state vowels in the temporal aspects of the discharge patterns of populations of auditorynerve fibers. J Acoust Soc Am 66:1381-1403. CrossRef Medline

Yu YQ, Xiong Y, Chan YS, He J (2004) Corticofugal gating of auditory information in the thalamus: an in vivo intracellular recording study. J Neurosci 24:3060-3069. CrossRef Medline

Zhang L, Jones EG (2004) Corticothalamic inhibition in the thalamic reticular nucleus. J Neurophysiol 91:759-766. Medline

Zhang Y, Yan J (2008) Corticothalamic feedback for sound- specific plasticity of auditory thalamic neurons elicited by tones paired with basal forebrain stimulation. Cereb Cortex 18:1521-1528. CrossRef Medline

Zhang Y, Suga N, Yan J (1997) Corticofugal modulation of frequency processing in bat auditory system. Nature 387:900-903. CrossRef Medline

Zychaluk K, Foster DH (2009) Model-free estimation of the psychometric function. Atten Percept Psychophys 71:1414-1425. CrossRef Medline 